\title{
Thermoluminescence as a Research Tool to Investigate Luminescence Mechanisms
}

\author{
Adrie J. J. Bos \\ Luminescence Materials, Faculty of Applied Sciences, Delft University of Technology, 2629JB Delft, \\ The Netherlands; a.j.j.bos@tudelft.nl; Tel.: +31-(0)15-278-4705
}

Received: 27 September 2017; Accepted: 23 November 2017; Published: 26 November 2017

\begin{abstract}
Thermally stimulated luminescence (TSL) is known as a technique used in radiation dosimetry and dating. However, since the luminescence is very sensitive to the defects in a solid, it can also be used in material research. In this review, it is shown how TSL can be used as a research tool to investigate luminescent characteristics and underlying luminescent mechanisms. First, some basic characteristics and a theoretical background of the phenomenon are given. Next, methods and difficulties in extracting trapping parameters are addressed. Then, the instrumentation needed to measure the luminescence, both as a function of temperature and wavelength, is described. Finally, a series of very diverse examples is given to illustrate how TSL has been used in the determination of energy levels of defects, in the research of persistent luminescence phosphors, and in phenomena like band gap engineering, tunnelling, photosynthesis, and thermal quenching. It is concluded that in the field of luminescence spectroscopy, thermally stimulated luminescence has proven to be an experimental technique with unique properties to study defects in solids.
\end{abstract}

Keywords: thermoluminescence; trap depth; energy level; rare earth ions; persistent luminescence; band gap engineering; tunnelling; photosynthesis; thermal quenching

\section{Introduction}

In recent decades, the search for new luminescent materials has been intensified due to applications in many different fields, like light emitting diode (LED) based lighting systems, persistent luminescence phosphors, storage phosphors, scintillators, and up and down conversion materials for solar cells. Progress in the identification of new luminescent materials requires insight into the underlying mechanisms and the role of the defects in those materials. Achieving this insight requires instrumentation and dedicated experimental methods.

Thermally stimulated luminescence (TSL) is light produced by heating a solid to a temperature below that of incandescence. The light is only observed after exposure of the solid to radiation, i.e., absorption of energy from an external source. The heat only works as a trigger. The main application of TSL is in radiation dosimetry since it has been shown that for some materials, the emitted light is proportional to the absorbed dose to which the material has been exposed. This is the case not only in personal dosimetry, but also for environmental, clinical, and high dose dosimetry. Another important application is using TSL as a dating method complementary to radiocarbon. TSL is able to date inorganic materials, mainly ceramics, while radiocarbon is limited to organic materials. TSL dating has also turned out to be useful in fields different from archaeology and historical architecture, in particular, the dating of sediments.

However, it was recognized in the fifties of the last century that TSL can not only be used for dosimetry and dating, but also for other purposes like measuring the efficiency of surface catalysts and determining impurities in rocks [1]. Thermoluminescence is extremely sensitive to defects in the material under investigation and can therefore also be used to study these defects. As the 
instrumentation developed further, it became clear that TSL could also be used in material science [2,3]. Recently, Mihóková and Nikl [4] reviewed spectroscopic methods, including TSL, to probe the excited state of emission centers. However, a review especially dedicated to the role of thermoluminescence as a research tool for the investigation of luminescent materials is lacking. This review briefly recalls the theoretical background and instrumentation and then uses a range of examples to show how thermoluminescence studies can be effective in revealing the luminescent mechanism for a variety of research problems.

\section{Theoretical Background}

In order to understand how thermoluminescence (TL) can be used to study luminescent materials, a theoretical background of the phenomenon is indispensable. The following discussion borrows heavily from references [5-9].

The basic effect leading to the production of TL is the trapping of charge carriers, i.e., electrons and holes, produced during exposure to an external source at defect sites in the material. Defect sites can be divided into two categories: (1) those inherently present in the material; and (2) those produced by external means, such as deliberately doping the sample with impurities. A well-known example of the first category is a negative ion vacancy. Such a vacancy can trap an electron and is then called an $F$ center. An example of the second category is a lattice vacancy caused by a higher valence impurity ion at the position of a lattice ion. A trivalent cation impurity in a divalent lattice, for example, would induce the formation of a cation vacancy in the lattice to maintain charge neutrality. Cationic vacancies are potential sites for trapping holes. There are many other types of defects that can act as electron or hole trapping centers. Revealing the nature of those defects is part of the research of luminescent materials.

Heating of the material causes the release of the trapped charge carriers and the recombination of electrons and holes at a luminescent center. The release of some of the stored energy excites the center and relaxation may lead to the emission of light. The nature of the luminescent center can be revealed by measuring the emission spectrum which is in many cases characteristic for a specific element. We note that not every recombination event leads to luminescence. If, for example, there is not enough energy available to excite the center, the recombination will be non-radiative. The process leading to recombination includes, in many cases, the transition of charge carriers through the conduction or valence band, but localized transitions may also take place. The theory of TSL consists of solving the relevant sets of coupled differential equations, describing the charge transfer. In the following, we discuss the simplest model. This model shows all the characteristics of the TSL phenomenon.

\subsection{Simple Model and Characteristics of TSL}

The simplest model to explain TL is the One Trapping centre One Recombination (OTOR) model (Figure 1). Absorption of radiant energy with energy greater than the band gap results in the ionisation of valence electrons, producing energetic electrons and holes which will, after thermalization, produce free electrons in the conduction band and free holes in the valence band. A certain percentage of the freed charge carriers will be trapped: the electrons at $\operatorname{Tr}$ and the holes at $R$ (transitions $b$ ). There is a certain probability that the charge carriers escape from these traps due to thermal stimulation. The probability per unit time of release of an electron from the trap, $p$, is assumed to be described by the Arrhenius Equation (1):

$$
p=s \exp \left(-\frac{E}{k T}\right)
$$

The pre-exponential factor $s$ is called the frequency factor or attempt-to-escape factor. In the simple model, the factor $s$ is considered as a constant (not temperature dependent) with a value in the order of the lattice vibration frequency, namely $10^{12}-10^{14} \mathrm{~s}^{-1}$. 


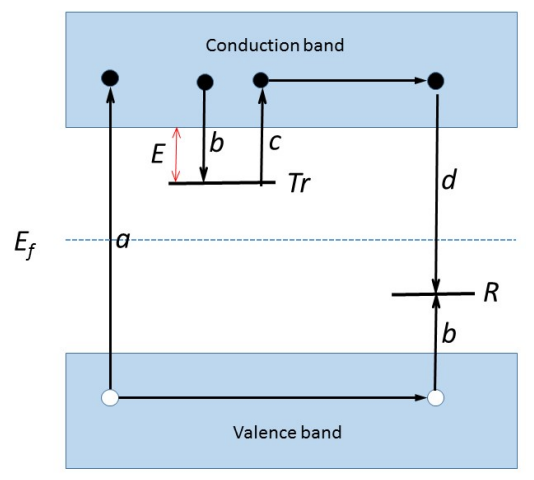

Figure 1. A simplified model of the thermoluminescence mechanism: During the excitation stage (a) electrons and holes are produced which are trapped (b) in trapping, Tr, and Recombination centers, $R$. During the heating stage (c) electrons are released to the conduction band and move through the Conduction band until they encounter a hole in a recombination center $(\mathbf{d})$. The recombination energy will excite the center and relaxation of the excited center will produce the luminescence. For explanation of $E$ and $E_{f}$ see text.

$E$ is called the trap depth or activation energy, which is the energy needed to release an electron from the trap into the conduction band (see Figure 1). The other symbols have their usual meaning; $k=$ Boltzmann's constant $=8.617 \times 10^{-5} \mathrm{eV} / \mathrm{K}$, and $T$ is the absolute temperature. The quantities $E$ and $s$ are called the trap parameters. Their values determine whether the electron will escape at a certain temperature $T$. If the trap depth $E>>k T_{0}$, with $T_{0}$ representing the temperature at irradiation, then any electron that becomes trapped will remain so for a long period of time, so that even after exposure to the radiation, there will exist a substantial population of trapped electrons. Furthermore, because the free electrons and holes are created and annihilated in pairs, there must be an equal population of trapped holes at level $R$. Because the normal equilibrium Fermi level $E_{f}$ is situated below level $\operatorname{Tr}$ and above level $R$, these populations of trapped electrons and holes represent a non-equilibrium state.

The return to equilibrium can be speeded up by raising the temperature of the TL material above $T_{0}$. This will increase the probability of detrapping and the trapped electrons will now be released from the trap into the conduction band. The charge carrier migrates through the conduction band of the material until it undergoes recombination at recombination center $R$. In the simple model following Randall and Wilkins [10-12], this recombination center is a luminescent center where the recombination of the electron and hole leaves the center in one of its higher excited states. Return to the ground state is coupled with the emission of light quanta, i.e., thermoluminescence. However, it should be realized that not every de-excitation leads to the emission of light. The non-radiative transitions depend on the temperature. Sometimes, at higher temperatures, the TL is completely thermally quenched. In the simple model, it is assumed that there is no quenching and no retrapping, i.e., all electrons released into the conduction band give rise to recombination under the emission of light. Let us denote $n$ $\left(\mathrm{m}^{-3}\right)$ as the concentration of trapped electrons and $m\left(\mathrm{~m}^{-3}\right)$ as the concentration of holes trapped at $R$. Then, the TL intensity $I(t)$, in photons per unit volume and per unit time $\left(\mathrm{m}^{-3} \mathrm{~s}^{-1}\right)$ at any time $t$ during heating is proportional to the rate of recombination of holes and electrons at $R$. This rate of recombination is, under the mentioned assumptions, equal to the rate of thermal excitation of electrons from $T r$ into the conduction band:

$$
I(t)=-\frac{d m}{d t}=-\frac{d n}{d t}=n p=n s \exp \left(-\frac{E}{k T}\right)
$$

This differential equation [2] describes the charge transport in the lattice as a first-order process. Usually, TL is observed as the temperature $T$ is raised as a linear function of time according to:

$$
T(t)=T_{0}+\beta t
$$


with $\beta\left(\mathrm{K} \mathrm{s}^{-1}\right)$ representing a constant heating rate and $T_{0}$ indicating the temperature at time $t=0$. Solving Equation (2) with this temperature profile leads to the well-known Randall-Wilkins equation:

$$
I(T)=-\frac{1}{\beta} \frac{d n}{d t}=n_{0} \frac{s}{\beta} \exp \left(-\frac{E}{k T}\right) \exp \left[-\frac{s}{\beta} \int_{T_{0}}^{T} \exp \left(-\frac{E}{k T^{\prime}}\right) d T^{\prime}\right]
$$

with $n_{0}$ representing the total number of trapped electrons at $t=0$ and $T^{\prime}$ indicating a dummy variable. This equation describes the shape of a peak. Such a peak shape can be understood as follows: as the temperature increases, the intensity initially increases because of the detrapping of the trapped charge carriers and the consequent recombination which initiates luminescence, after which point the intensity reaches a maximum and finally decreases as the number of charge carriers becomes depleted. The shape and position of the peak maximum are governed by the trap parameters (material constants) and the heating rate (readout parameter).



Figure 2. TL glow peaks calculated with the Randall-Wilkins Equation (4) for $n_{0}=10^{14} \mathrm{~m}^{-3}$; $s=10^{11} \mathrm{~s}^{-1}, \beta=1 \mathrm{~K} / \mathrm{s}$ and different values of the trap depth $E$.

In Figure 2, the shape of the so-called glow peak according to Equation (4) is shown for different values of the trap depth $E$, while the other parameters are kept constant. We see that for deeper traps: (i) the glow peak temperature shifts to a higher temperature which corresponds with the thought that the deeper the trap, the more energy needed to release the charge carrier; and (ii) the luminescence is spread out over a wider temperature interval resulting in a broader glow peak. The total intensity, the area of the glow peak equal to $n_{\mathrm{o}}$, remains the same since this value only depends on the absorbed dose delivered before the readout. The shift of the glow peak temperature shows the sensitivity of the TL method: a difference in trap depth of only $0.05 \mathrm{eV}$ gives a difference in glow peak temperature of an easy to measure $20 \mathrm{~K}$ (for the parameter values mentioned in Figure 2). The intensity $I_{m}$ at the temperature of the glow peak maximum, $T_{m}$, can be described by [13]:

$$
I_{m}\left(T_{m}\right)=n_{0} \frac{\beta E}{k T_{m}^{2}} \exp \left(-g_{m}\right) \sim \frac{n_{0}}{T_{m}}
$$

with $g_{m}=g\left(E / k T_{m}\right)$ and $g=g(E / k T)$, an exponential integral with a value very close to unity for $T=T_{m}$ is seen. As we will see below, the ratio $E / T_{m}$ is almost constant so that with Equation (5), we deduce that $I_{m} \sim n_{0} / T_{m}$. For deeper traps (increase of $T_{m}$ ), the height of the glow peak decreases while the area under the curve $\left(\sim n_{0}\right)$ remains the same, resulting in an increase of the width of the peak. The shape of the glow peak also depends on the heating rate with which the TL material is read out (see Figure 3). 
The temperature of the maximum in terms of trap parameters $E$ and $s$ and the heating rate $\beta$ can be found by equating the derivative of Equation (4) to zero which yields:

$$
\frac{\beta E}{k T_{m}^{2}}=s \exp \left(-\frac{E}{k T_{m}}\right)
$$

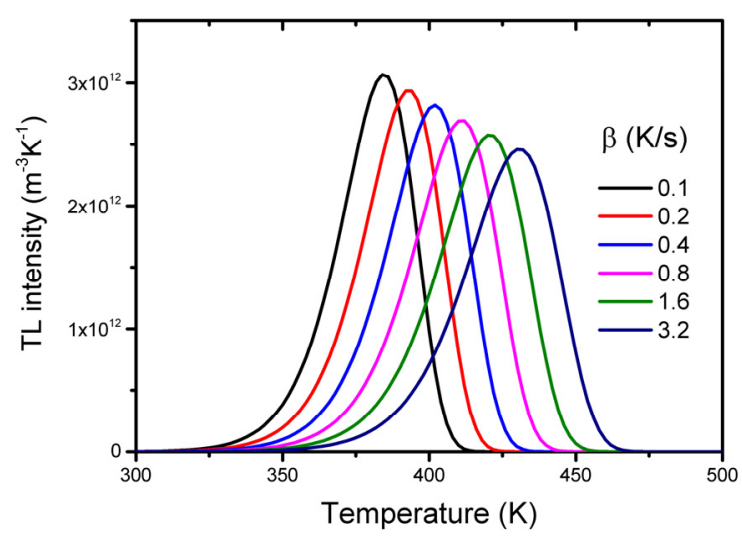

Figure 3. TL glow peaks calculated with the Randall-Wilkins Equation (4) for $n_{0}=10^{14} \mathrm{~m}^{-3}$; $s=10^{11} \mathrm{~s}^{-1}, E=1 \mathrm{eV}$ and different values of the heating rate $\beta$.

From this equation, it follows that the glow peaks are shifted towards higher temperatures when the heating rate is increased. This can be understood as follows. A TL glow peak results from two factors, which change in opposite directions when the time elapses, i.e., the temperature increases, resulting in: (i) an increased escape probability and so a higher rate of recombination, leading to an increased number of photons emitted; and (ii) a decreased number of charge carriers available for recombination. At a lower heating rate, more time elapses during the same temperature increase, allowing more recombination events to occur, so that the charge pairs (electrons and holes) are eliminated faster and the TL maximum is reached at a lower temperature. From Equation (6), it can be derived that the relation between $T_{m}$ and the heating rate $\beta$ can be approximated by:

$$
T_{m}=a+b \ln \beta
$$

with $a$ and $b$ representing constants depending on the activation energy $E$ and frequency factor $s$. From this relation, it follows that the shift of $T_{m}$ with the heating rate is only pronounced if the heating rate is changed significantly. A typical value is $10 \mathrm{~K}$ for any doubling of the heating rate. For deeper traps, it is more than for shallow traps. For lower frequency factors, it is also higher.

Calculation of the trap depth from given $T_{m}$ and $s$ is hampered by the fact that Equation (6) is transcendental and the equation should be solved by iteration. However, Equation (6) can also be re-written as:

$$
E=\frac{s}{\beta}\left\{T_{m} \exp \left(-\frac{E}{k T_{m}}\right)\right\} k T_{m}
$$

It appears that in a wide range of trap depths and for a fixed ratio $s / \beta$, the product $\left\{T_{m} \exp \left(-E / k T_{m}\right\}\right.$ is constant within a few percent. Thus, for a given $s$ and $\beta$, the trap depth $E$ is quite accurately proportional to $T_{m}$. This is illustrated in Figure 3, where $E$ is plotted against $T_{m}$ for a wide range of values of the ratio $s / \beta$. We see that in good approximation we can write:

$$
E=C_{U} k T_{m}
$$

The constant of proportionality $C_{U}$ is called the Urbach constant, since Urbach [14] assumed that, no matter the sample, we can use $E(e V)=T_{m}(K) / 500=23 k T_{m}$. Although dimensionless, $C_{U}$ is not a 
constant. From Figure 4 , we see that $C_{U}$ varies between 18 and 44 depending on the ratio $s / \beta$. The numerical value of the Urbach constant shows that an average thermal energy of $3 / 2 k T$ with $k T$ as the lattice vibrational energy, is by far not enough for an electron to escape from the trap. However, the energy is distributed according to a Maxwell-Boltzmann distribution. The high value of the Urbach constant means that only a small number in the tail of the Maxwell-Boltzmann distribution exceeds the energy needed to escape. It results in a sensitivity of the peak maximum position for variation of the trap depth between $26 \mathrm{~K}$ and $64 \mathrm{~K}$ per $0.1 \mathrm{eV}$.

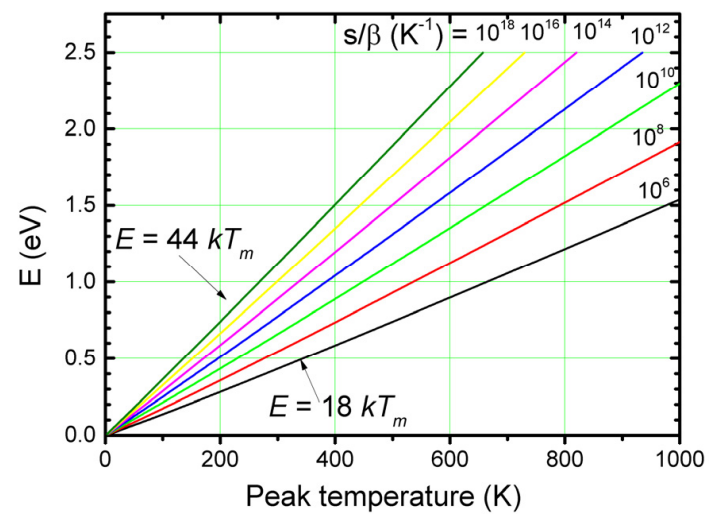

Figure 4. Trap depth $E$ calculated with Equation (6) as a function of the peak temperature for a wide range of values of the ratio $s / \beta$.

Thermally stimulated luminescence is also sensitive in the sense that the number of trapping centers needed to detect TL is low. Defect densities as low as $10^{7} \mathrm{~cm}^{-3}$ can produce a measurable TL signal, whereas techniques such as Electron Paramagetic Spectroscopy (EPR) and Optical Absorption Spectroscopy (OAS) are only sensitive for higher defect concentrations of $10^{12} \mathrm{~cm}^{-3}$ or more $[2,15]$. Finally, we like to mention that thermoluminescence is a phenomenon that can be observed from materials in various appearances. It is not restricted to single crystalline material. Non-crystalline solids can be used as well. Because of the high sensitivity, only $20 \mathrm{mg}$ of material is usually enough to produce a measurable signal. These properties make TSL a very useful technique in material research.

\subsection{Deviations from the Simple Model}

The simple model is not realistic. In real TL materials, the number of trapping states is, in general, more than one. Some of these states are related to intrinsic defects of the host material, whilst other centers are dopants deliberately added during the synthesis. Within one material, there could also be different luminescent centers present, for example, $F$-centers and dopants in the form of lanthanides ions. As a consequence, the charge traffic in the material will be much more complicated than depicted in Figure 1. We will only briefly describe some possibilities. For a deeper and quantitative treatment, the reader is referred to textbooks [6-9].

In the simple model, it is assumed that in the heating stage, the electron is released to the conduction band where it moves relatively freely until it encounters a hole center where it recombines. A possibility that is studied extensively in the literature is that the released electron has two options: recombination followed by luminescence or to be retrapped by a vacant trap center. It can be shown that retrapping leads to non-first-order kinetics and this will affect the shape of the glow curve. A typical property of non-first-order behavior is that the glow peak maximum shifts to a lower temperature as the absorbed dose, i.e., the number of produced free electrons and holes, increases. Not only the maximum shifts, but the entire shape of the glow curve, changes with an increasing dose. However, the experience of many years of study of TL materials showed that for many materials, the temperature of the glow peak maximum of individual glow peaks remains practically constant over a wide dose range, and there are no systematic changes in the glow curve shapes with the irradiation 
dose. Sunta [9], page 71, states that, "In fact as far as our experience goes, we have not come across any material which shows a non-first-order behaviour by peak shift change in dose." Lewandowski and McKeever have given a physical justification for why a first-order process dominates in nature using a generalized description of thermally stimulated processes. Pagonis and Kitis [16] have shown that the presence of many competitive processes during the heating stage of TL may be correlated to the remarkable stability of the glow curve shapes exhibited by most materials, and to the prevalence of first-order kinetics.

The prevalence in nature of first-order kinetics does not mean that every glow curve can be described with Equation (4). The simple model of Figure 1 assumed that the trap depths associated with localized states are single-valued in energy. In real materials, the trap depths associated with particular defects can be spread over a range of values, i.e., they tend to be distributed, rather than discrete. The result is that the glow peak is the sum of a large number of first-order glow peaks which emerges as one broad glow peak. The idea of a distribution of trap depths is as old as the theory of TL itself, as first suggested by Randall and Wilkins [10-12]. They showed that such distributions exit in calcites and dolomites. Quasi-continuous distributions of trap depths may be expected in non-crystalline materials, as a result of the large number of possible surroundings of the defects. Examples have been given for feldspars [17], Ca-Be rich aluminosilicate (Bavenite) [18], and chariote silicate, a gemstone material [19]. They have also been presented for synthetic materials for dosimetry like $\mathrm{CaSO}_{4}: \mathrm{Dy}$ [20], $\mathrm{Li}_{2} \mathrm{~B}_{4} \mathrm{O}_{7}: \mathrm{Cu}$ [21], $\mathrm{Al}_{2} \mathrm{O}_{3}: \mathrm{C}$ [22] and persistent luminescent phosphors like $\mathrm{SrAl}_{2} \mathrm{O}_{4}: \mathrm{Eu}, \mathrm{Dy}$ [23], $\mathrm{SrAl}_{2} \mathrm{O}_{4}: \mathrm{Eu}$ [24], $\mathrm{CaAl}_{2} \mathrm{O}_{4}: \mathrm{Eu}, \mathrm{Nd}$ [25], $\mathrm{Zn}_{x} \mathrm{Ga}_{2} \mathrm{O}_{3+x}: \mathrm{Cr}^{3+}$ [26,27], $\mathrm{Ca}_{6} \mathrm{BaP}_{4} \mathrm{O}_{17}: \mathrm{Eu}^{2+}, \mathrm{R}^{3+}(\mathrm{R}=\mathrm{Dy}, \mathrm{Tb}, \mathrm{Ce}, \mathrm{Gd}, \mathrm{Nd})[28]$, and $\mathrm{Ba}_{2} \mathrm{Si}_{5} \mathrm{~N}_{8}: \mathrm{Eu}^{2+}$ [29], as well as for scintillators GAGG:Ce and LuAG:Pr [30].

Another deviation from the simple model that should be mentioned involves the number of centers. In general, a real TL material will show more than one single electron trap. Not all these traps will be active in the temperature range in which the sample is heated. It could be that electrons in the deeper trap are unaffected. However, their trap filling will affect the TL signal. Something similar can be said for the number and behaviour of recombination centers.

In principle, it is possible to set up a model with different traps and recombination centers and write down the rate equations that describe the charge traffic. But it is clear that the more traps and recombination centers are involved, the more parameters, like trapping and recombination probabilities and the concentration of trapping and recombination states, will be necessary. Determining all these parameters from the shape of the TL glow curve is tedious work.

\subsection{Methods for Extracting Trap Parameters}

A number methods have been developed for evaluating the activation energy from the shape of the TL peak. The simplest one is in the case where the frequency factor $s$ is already known from another experiment like Raman spectroscopy. By determining $T_{m}$ from the glow curve and using Equation (8), the trap depth $E$ can then easily be calculated. When studying the effect of various dopants in a host material, this method is an easy and powerful method. Examples are given by Lecointre et al. [31] for $\mathrm{YPO}_{4}: \mathrm{Pr}^{3+}, \mathrm{Ln}^{3+}(\mathrm{Ln}=\mathrm{Nd}, \mathrm{Er}, \mathrm{Ho}, \mathrm{Dy})$ and Luo et al. [32] for $\mathrm{RE}_{2} \mathrm{O}_{2} \mathrm{~S}(\mathrm{RE}=\mathrm{La}, \mathrm{Gd}, \mathrm{Y}$, and Lu).

Another method involves the shift of the maximum temperature $T_{m}$ while changing the heating rate $\beta$. Hoogenstraaten [33] suggested measuring the glow curve for several heating rates. Considering Equation (6), it can be seen that a plot of $\ln \left(T^{2}{ }_{\mathrm{m}} / \beta\right)$ versus $\left(1 / T_{m}\right)$ should yield a straight line, from the slope of which, $E / k$, the activation energy $E$ can be determined. Although this method has been shown to be valid for the first-order situation, it has been demonstrated that this method is rather general. Since the shift of $T_{m}$ varies with $\ln \beta$ (see Equation (7)), one should vary the heating rate over several orders of magnitude to get an accurate result. In applying this method, one should also realize that during TL readout with readers using contact heating, the temperature of the sample differs from the measured temperature of the heating element. Kitis and Tuyn [34] have developed a method to approximate this so-called temperature lag based on: 


$$
T_{m j}=T_{m i}-c \ln \left(\frac{\beta_{i}}{\beta_{j}}\right)
$$

where $T_{m j}$ and $T_{m i}$ are the maximum temperatures of the glow peak at heating rates $\beta_{j}$ and $\beta_{i}$, respectively, and $c$ is a constant. The constant $c$ can be approximated by $c=\left(T_{m 2}-T_{m 1}\right) / \ln (2)$, where $T_{m 2}$ and $T_{m 1}$ are the temperatures corresponding to heating rates 1 and $2 \mathrm{~K} / \mathrm{s}$, i.e., two heating rates where the lag can be neglected. The temperature lag $\Delta T=T_{m j}-T_{m i}$ can be used to correct the temperature at higher heating rates. The lag can be considerable. For a $0.9 \mathrm{~mm}$ thick LiF sample measured at a heating rate of $\beta=6 \mathrm{~K} / \mathrm{s}$, the temperature lag is already $14 \mathrm{~K}$ [35].

A method suggested by Garlick and Gibson [36] is called the "initial-rise" method. If we consider Equation (2), at the low temperature end of the peak, $n$ varies only slightly, and so we can write:

$$
I(T) \sim \exp \left(-\frac{E}{k T}\right)
$$

A plot of $\ln (I)$ as a function of $1 / T$ in the low temperature ranges should yield a straight line, the slope of which is $-E / k$ from which $E$ can be calculated. The method is independent of the kinetic order of the process. The main problem here is that the initial-rise range is limited. Pagonis et al. [37] take $I$ to be smaller than about $15 \%$ of the maximum TL intensity. Chen en Haber [38] use the $5-10 \%$ intensity range. In this range, the intensity is low and this may be a significant restriction. But the method is simple and can be successfully used to extract trap depth distributions [25].

A method that has been used extensively is the curve-fitting method. Generally speaking, one compares the shape of the measured TL peak with a theoretical curve, like Equation (4), with the appropriate number of parameters. Horowitz and Yossian [39] have provided an extensive and detailed review of the subject. One has to guess the number of overlapping peaks in a given glow curve in order to perform the analysis. Either first-order or general-order kinetics must be assumed, and the deconvolution program minimizes the difference between the experimental and generated curves, thus yielding the trap parameters of the individual peaks. However, one should be aware that often, the computer produces fit parameters which have no relation with the physical quantities one likes to extract. In the first place, one has to realize that the trap parameters $E$ and $s$ are highly correlated. This implies that several pairs of $E$ and $s$ produce almost the same fit. Van Dijk [40] calls the glow curve deconvolution problem, from a numerical point of view, ill-conditioned. For a single first-order peak, the least squares function is, in the $E-\ln (s)$ plane, a very narrow valley of which the bottom is only slightly curved. This was recently experimentally confirmed by Stadtmann and Wilding [41] for the glow peaks of LiF:Mg,Ti. Secondly, if several overlapping glow peaks are involved, the glow curve analysis method assumes that the principle of the superposition is valid. This is only the case for first-order glow peaks. Non-first-order processes imply interaction between the trapping centers which are not taking into consideration by fitting with the sum of a number of non-first-order glow peaks. Thirdly, in a real material, there are usually more trapping centers involved. Chen et al. [42] have shown by simulation that for a model with three trapping centers and one kind of recombination center, two overlapping TL glow peaks may occur, which together look like a first-order peak, but with an anomalous low evaluated trap depth and frequency factor. In a similar simulation, extremely high trap depths and frequency factors could be found for a model with one trapping state and three recombination centers, one radiative and two non-radiative [43]. These simulations show that that one has to be very cautious in the interpretation of the fit parameters. In many cases, they characterize the glow curve under certain experimental conditions but do not reflect kinetic properties of the TL traps.

To determine all the trapping parameters is practically not achievable. However, it should be noted that for many cases, the energy level, i.e., the trap depth, is the most important one. This parameter plays a special role among the other parameters. Due to its appearance in the Arrhenius exponent, the shape and the position on the TL glow peak depends vary strongly on this parameter. One can 
determine the value of $E$ with a good accuracy without knowing the other parameters. For an example, see page 506 of [7].

\section{Instrumentation}

The three main components of TL recording equipment comprise a sample chamber with a temperature controlled heating system, a light detector, and signal processing equipment. The level of sophistication of the components depends on the application.

The heart of the reader is the heating system. It should provide reproducible and controllable heating profiles. The usual mode of heating is by passing a high current through a thin, low impedance strip of tantalum or platinum, the planchet. The sample (powder of solid chip) is placed in direct contact with the planchet, the temperature of which is monitored via a thermocouple spot welded at the bottom of the planchet. To ensure close thermal contact between the sample and the planchet, the sample is heated in an inert gas atmosphere while the heating rate is below $1 \mathrm{~K} / \mathrm{s}$. Most applications of TL, like in dosimetry, are applied above room temperature (RT). This will prevent the observation of TL of very shallow traps which are normally empty at RT. Low temperature measurements may reveal defect centers which play an important role, for example, in scintillators [30]. For low temperature TL measurements, the sample chamber is a cryostat with a heating system that operates in a vacuum. To ensure good thermal contact is, in this case, even more difficult. Irradiations must be carried out at a low temperature and in a vacuum, and thus a window (typically a thin Be window) must be mounted on the cryostat. TL is also used for the study of photosynthesis in intact leaves, and algal and cyanobacterial cells $[44,45]$. These studies require a very specific instrumental feature: the possibility to cool the sample well below $0{ }^{\circ} \mathrm{C}$, while a vacuum is not possible [46].

The second important component of the TL reader is the detection of the light emitted during the heating. In material research, it is essential to measure the emission spectrally resolved, i.e., with a spectrometer [47-51]. The result is a so-called 3D TL plot: the TL intensity as a function of temperature and wavelength. Figure 5 shows an example. The contour plot reveals that the low temperature glow peak mainly originates from $\mathrm{Sm}^{3+}$ emission, while the high temperature peak stems from $\mathrm{Ce}^{3+}$ emission. If the emission center is known, one can measure the light with a much more sensitive photomultiplier tube (PMT) through a filter that transmits the wavelength or wavelengths of the emission center.

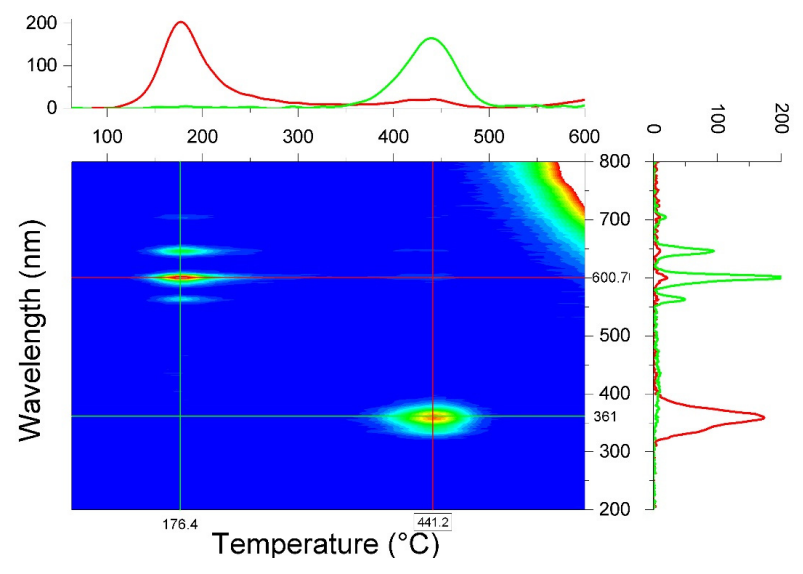

Figure 5. Contour plot of TL intensity as a function of temperature and wavelength of $\mathrm{YPO}_{4}: \mathrm{Ce}^{3+}, \mathrm{Sm}^{3+}$ after $9.6 \mathrm{kGy}{ }^{60} \mathrm{Co}$ irradiation and read out at $5{ }^{\circ} \mathrm{C} / \mathrm{s}$. The figure on the top shows two glow curves in red and green for, respectively, emission wavelengths of $601 \mathrm{~nm}\left(\mathrm{Sm}^{3+}\right.$ emission) and $361 \mathrm{~nm}$ $\left(\mathrm{Ce}^{3+}\right.$ emission). The figure on the right shows two emission spectra in red and green at, respectively, $441^{\circ} \mathrm{C}$ and $176^{\circ} \mathrm{C}$. The TL intensity at high temperatures and long wavelengths is from black body radiation. [52]. 
Excitation of the sample can be performed with various irradiation sources: radioactive sources, an X-ray generator, and UV-VIS lamps. Sometimes, the source is integrated in the TL reader which makes the automation of a series of TL readouts possible. Important information can be extracted by measuring the so-called TL excitation spectrum. In this case, the sample is excited with monochromatic light obtained from a UV-VIS source coupled to a monochromator. After excitation with a certain wavelength, the sample is heated and the TL recorded. This measurement is repeated for a series of different excitation wavelengths. By plotting a selected glow peak area as a function of the excitation wavelength (corrected for variations in lamp spectrum), the TL excitation spectrum for that glow peak is obtained [53].

TL-readers equipped with all sorts of possibilities in excitation and detection are commercially available. A well-known reader is the Risø-reader. Recent developments of that reader are described by Thomson et al. [54] and Lapp et al. [55,56]. Another luminescence measurement system-lexsyg — which can be used in fundamental material research, is developed by Freiberg Instruments [57-59].

\section{Thermoluminescence as a Research Tool}

The characteristics of a luminescent material strongly depend on the position of the energy levels of the defect levels with respect to the bottom of the conduction band and the top of the valence band. The position of the defect levels also controls whether those defects can act as an electron donor or electron acceptor, or as a hole trap or electron trap. Accurate information on the location of defect levels within the band gap is not easy to obtain. In the following, we will give a series of examples where TSL measurements can help to locate these levels, first from the defect levels of the widely used lanthanides and next from transition metals.

\subsection{Energy Level Positions}

Lanthanides are widely used as luminescence activators in inorganic compounds. Dorenbos [60-63] has developed a phenomenological model predicting the absolute location of $4 f$ and $5 d$ states of lanthanides in different compounds. The model predicts all $4 f$ and $5 d$ ground state levels of both the divalent and trivalent lanthanides in a compound with only three parameters. With those level positions, one can predict the behaviour of the centers. For example: when the divalent lanthanide $4 f^{n}$ ground state levels are below the conduction band, the corresponding trivalent ions may act as electron-trapping centers. As a function of the type of lanthanide codopant, there is predictable variation in the trap depth as given by a so-called zigzag curve. This behaviour was proposed by Dorenbos in 2005 [64] and later it was experimentally confirmed by TL studies of $\mathrm{YPO}_{4}: \mathrm{Ce}^{3+}, \mathrm{Ln}^{3+}$ $(\mathrm{Ln}=\mathrm{Pr}, \mathrm{Nd}, \mathrm{Sm}, \mathrm{Dy}, \mathrm{Ho}, \mathrm{Er}, \mathrm{Tm}$, and $\mathrm{Yb}$ ) by Bos et al. [65] (see Figure 6).

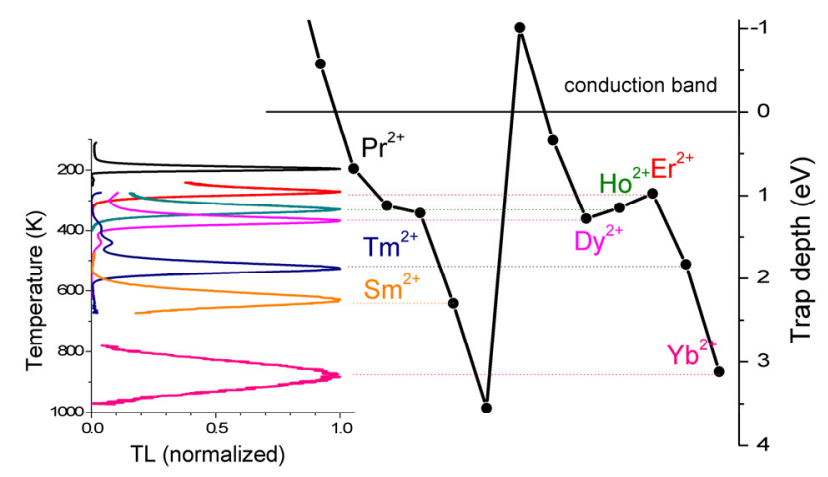

Figure 6. Comparison of predictions of the trap depth of the energy level scheme (the zigzag curve) and experimentally measured glow peak maxima. The codopant and corresponding glow peak have the same color. 
Here, $\mathrm{Ce}^{3+}$ acts as a hole trapping center and recombination (luminescent) center, while the various lanthanide co-dopants act as electron-trapping centers that trap electrons during the exposure to ionizing radiation. $\mathrm{Ln}^{3+}$ ions substitute the $\mathrm{Y}^{3+}$ ion. Because $\mathrm{Ln}^{3+}$ ions and $\mathrm{Y}^{3+}$ are both trivalent cations, no charge compensation is required. The trapping site for all $\mathrm{Ln}$ ions is therefore similar and so is the escape frequency $s$. For the same heating rate, the glow peak maximum temperature can be considered as directly proportional to the trap depth (conform Equation (9). If we replace $\mathrm{Ce}^{3+}$ in this host material by $\operatorname{Pr}^{3+}$ with lanthanides as codopants, the same results are obtained with $\mathrm{Pr}^{3+}$ as the luminescent center [31]. A similar study on the energy level positions was performed on $\mathrm{GdAlO}_{3}: \mathrm{Ce}^{3+}, \mathrm{Ln}(\mathrm{Ln}=\mathrm{Pr}, \mathrm{Er}, \mathrm{Nd}, \mathrm{Ho}, \mathrm{Dy}, \mathrm{Tm})$ (see Figure 7) and lanthanides in $\mathrm{Y}_{3} \mathrm{Al}_{5} \mathrm{O}_{12}$ [66], $\mathrm{LuPO}_{4}$ [67], and $\mathrm{Sr}_{3} \mathrm{AlSi}_{1-x} \mathrm{O}_{5}$ [68]. In all those cases, the position of the maximum of the glow peak could be connected to the trap depth. This energy level position could be connected to the Charge Transfer band in optical excitation spectra, confirming the systematic trends of the lanthanide energy levels found in the literature [60]. Today, it is well-established that the same shape of the zigzag curve always reappears in inorganic compounds. This property is used to design new dosimetric materials not on a trial and error base, but by systematic investigation [69,70].



Figure 7. Normalized thermally Stimulated luminescence glow curves of $\mathrm{GdAlO}_{3}: 1 \% \mathrm{Ce}^{3+}, 1 \% \mathrm{Ln}^{3+}$ $\left(\mathrm{Ln}=\mathrm{Er}, \mathrm{Nd}, \mathrm{Ho}, \mathrm{Dy}\right.$, and Tm). All glow curves were recorded by measuring the $\mathrm{Ce}^{3+}$ emission. Data obtained from Luo et al. [71].

TSL measurements can also help in determining the location of the $5 d$ levels of lanthanides relative to the bottom of the conduction band and the top of the valence band. This will be clarified with an example for the energy levels of $\mathrm{Ce}^{3+}$ and $\mathrm{Yb}^{3+}$ codoped $\mathrm{Y}_{3} \mathrm{~A}_{15} \mathrm{O}_{12}$ (YAG) [72]. In this well-known material, $\mathrm{Ce}^{3+}$ is the luminescent center. The co-dopant $\mathrm{Yb}^{3+}$ act as an electron trapping center. Thermoluminescence excitation spectroscopy (TLES) was used to establish the location of the energy levels of $\mathrm{Ce}^{3+}$. (see Figure 8a).

There are three strong bands peaked at $342 \mathrm{~nm}(3.63 \mathrm{eV}), 258 \mathrm{~nm}(4.81 \mathrm{eV})$, and $232 \mathrm{~nm}(5.34 \mathrm{eV})$ in the TLES with the illumination performed at room temperature (RT) (curve (a)). According to the optical absorption spectrum of YAG:Ce ${ }^{3+}$ [73] (Figure 8b), the three bands correspond to absorption bands of $\mathrm{Ce}^{3+}$. The fact that a TLES signal is observed implies that there is a significant $5 d_{2}$ electron escape probability to the conduction band. From this, we conclude that the $5 d_{2}$ level must be inside the $\mathrm{CB}$ or very close $(<0.1 \mathrm{eV})$ below the bottom of the $\mathrm{CB}$. Meanwhile, the $5 d_{1}$ state of $\mathrm{Ce}^{3+}$ is ascertained to lie below the bottom of the CB because no peak at about $457 \mathrm{~nm}(2.715 \mathrm{eV})$ is observed in the TLES. 

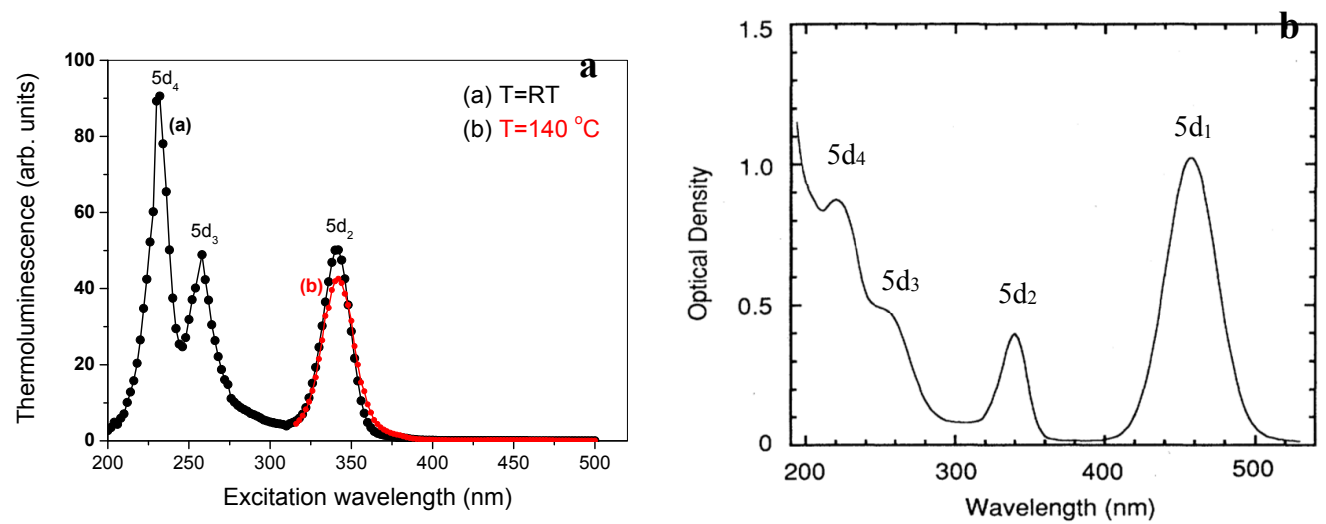

Figure 8. Thermoluminescent excitation spectrum (a from You et al. [72]) and optical absorption spectrum ( $\mathbf{b}$, adopted from Hamilton et al. [73]) of YAG:Ce ${ }^{3+}$. Note the absence in the $5 d_{1}$ band in the TLES spectrum.

The TLES with the illumination performed at an elevated temperature of $140{ }^{\circ} \mathrm{C}$ is also presented in Figure 8a (curve (b)). This temperature was chosen to be lower than $T_{m}$ in order to avoid thermal cleaning of the TL signal. After illumination, the sample was cooled down to RT and the TL glow curves were recorded. There is still no peak related to the ${ }^{2} F_{5 / 2} \rightarrow 5 d_{1}$ transition for the higher temperature measurement, confirming that the $5 d_{1}$ state of $\mathrm{Ce}^{3+}$ lies well below the CB.

The TL glow curve showed one main glow peak. With the variable heating rate method, a trap depth of $1.7 \mathrm{eV}$ was determined. The energy level diagram of $\mathrm{YAG}: \mathrm{Ce}^{3+}, \mathrm{Yb}^{3+}$ constructed from the derived energy locations is shown in Figure 9. This scheme provides important information on the energetically possible electron transfer pathways to and from $\mathrm{Ce}$ and $\mathrm{Yb}$ in $\mathrm{YAG}$. The position of the ${ }^{1} \mathrm{~S}_{0}$ ground state of $\mathrm{Yb}^{2+}$ is about $1.7 \mathrm{eV}$ below the bottom of the $\mathrm{CB}$, indicating that $\mathrm{Yb}^{3+}$ is a stable electron trap in YAG. Upon $\beta$-irradiation, $\mathrm{Yb}^{3+}$ captures an electron from the $\mathrm{CB}$, becoming $\mathrm{Yb}^{2+}$, while $\mathrm{Ce}^{3+}$ changes into $\mathrm{Ce}^{4+}$ by trapping a hole from the VB. During $\mathrm{TL}$, the trapped electron is thermally excited from $\mathrm{Yb}^{2+}$ to the CB. It is captured by $\mathrm{Ce}^{4+}$, resulting in an excited $5 d_{1}$ state of the $\mathrm{Ce}^{3+}$, as illustrated in pathway (1). Finally, the characteristic $5 d \rightarrow 4 f$ emission of $\mathrm{Ce}^{3+}$ is observed as a TL glow. The position of the $5 d_{1}$ level with respect to the conduction band gives an explanation of the thermal quenching of photoluminescence. The position of the same $5 d_{1}$ level with respect to the ${ }^{1} S_{0}$ level of $\mathrm{Yb}^{3+}$ makes pathway (2) possible. This non-localized transition competes with pathway (1), explaining why the TL increases with an increasing heating rate. Pathway (3) finally explains the fading behaviour of the TL.

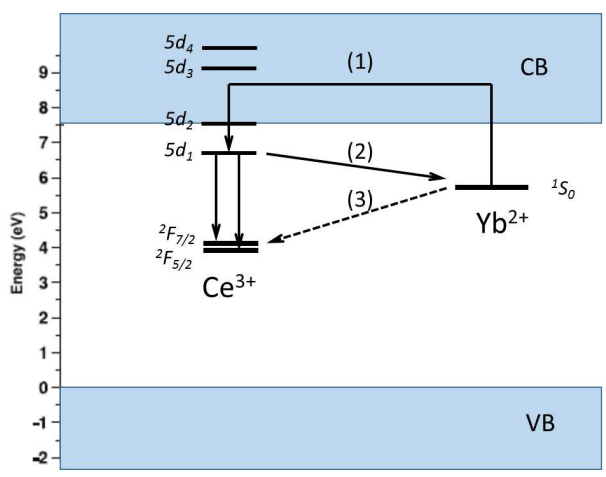

Figure 9. Energy level location of $\mathrm{Ce}^{3+}$ and $\mathrm{Yb}^{2+}$ in YAG. Pathways (1), (2), and (3) illustrate three different energetically possible electron transfer pathways to and from Ce and $\mathrm{Yb}$ in YAG (Adopted from You et al. [72]). $\mathrm{CB}=$ Conduction Band and VB = Valence Band. 
Other examples in which TSL measurements are used to determine the position of the $5 d$ excited levels with respect to the conduction band of $\mathrm{Ce}^{3+}$ are given by Babin et al. [74] and $\mathrm{Wu}$ et al. [75].

\subsection{Persistent Luminescence}

Persistent luminescence, also called afterglow, is the phenomenon whereby luminescence can last for a certain period of time, from seconds to many hours, after stopping the excitation. The luminescence mechanism is similar to that for thermoluminescence. In fact, persistent luminescence can be considered as TL at room temperature. To design new persistent phosphors, it is important to know the role of the defects (donor or acceptor) and the energy level location. In the most well-known afterglow phosphor, $\mathrm{SrAl}_{2} \mathrm{O}_{4}: \mathrm{Eu}^{2+}, \mathrm{Dy}^{3+}[76]$, the $\mathrm{Eu}^{2+}$ ions are the recombination centers, while $\mathrm{Dy}^{3+}$ plays a role in the trapping. Other trivalent lanthanide $(\mathrm{Ln})$ ions are used as co-dopant, which results in other persistent luminescence properties. Similarly, transition metal ions $\left(\mathrm{TM}^{2+}\right)$ with different $d$ electrons can be used. Ueda et al. [77] have carried out a systematic study into the role of $\mathrm{TM}^{3+}, \mathrm{TM}=\mathrm{Sc}, \mathrm{Ti}, \mathrm{V}, \mathrm{Cr}, \mathrm{Fe}$ in $\mathrm{Y}_{3} \mathrm{Al}_{2} \mathrm{Ga}_{3} \mathrm{O}_{12}: \mathrm{Ce}^{3}, \mathrm{TM}^{3+}$, where $\mathrm{Ce}^{3+}$ is a hole trapping center. The TL glow curves for the different co-dopants are shown in Figure 10. It shows that they act as suitable electron traps like co-dopants of trivalent lanthanides ions in $\mathrm{YPO}_{4}: \mathrm{Ce}^{3+}, \mathrm{Ln}^{3+}$. Again, TL is shown to be a sensitive technique to determine energy levels in the band gap and is therefore widely used in the study of persistent luminescence phosphors, as illustrated by the many publications in this field $[28,29,78-96]$.

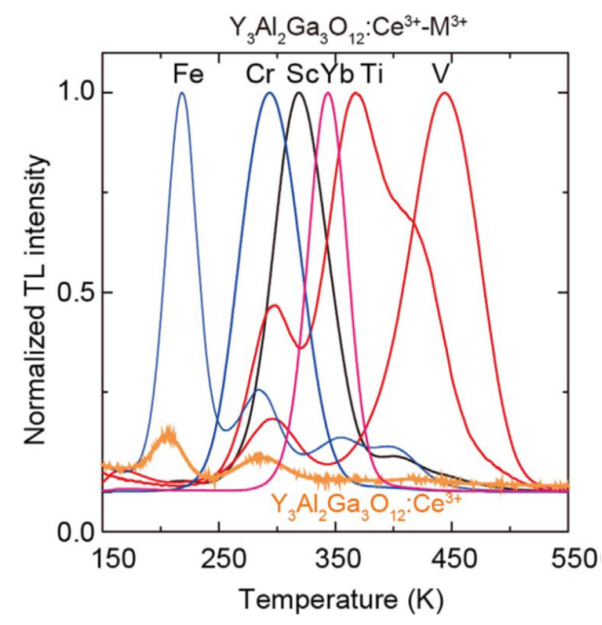

Figure 10. Normalized TL glow curves recorded with a $10 \mathrm{~K} / \mathrm{min}$ heating rate of $\mathrm{Y}_{3} \mathrm{Al}_{2} \mathrm{Ga}_{3} \mathrm{O}_{12}: \mathrm{Ce}^{3+}$ $\mathrm{TM}^{3+}(\mathrm{TM}=\mathrm{Sc}, \mathrm{Ti}, \mathrm{V}, \mathrm{Cr}, \mathrm{Fe}), \mathrm{Y}_{3} \mathrm{Al}_{2} \mathrm{Ga}_{3} \mathrm{O}_{12}: \mathrm{Ce}^{3+}-\mathrm{Yb}_{3+}$, and $\mathrm{Y}_{3} \mathrm{Al}_{2} \mathrm{Ga}_{3} \mathrm{O}_{12}: \mathrm{Ce}^{3+}$ after $\mathrm{UV}$ charging at 100 K. Reproduced from [77].

\subsection{Band Gap Engineering}

Afterglow is the property of interest in persistent luminescent phosphors. In the development of new phosphors, one will try to improve the luminescent intensity and extend the duration. However, in a scintillator material, this property is responsible for degradation of the scintillation performance.

In LuAG:Ce, for example, TL measurements suggest that the cation antisites induce shallow traps responsible for the afterglow [98]. To suppress the effect of these shallow traps, Fasoli et al. applied a technique called band gap engineering [97]. When LuAG is admixed with $\mathrm{Ga}^{3+}$, the band gap gets smaller and the defect level is enveloped by the conduction band (see Figure 11). This clearly improved the scintillator response time. To investigate the conduction band shift as a consequence of the Ga admix, TSL measurements were crucial. 
LUAG

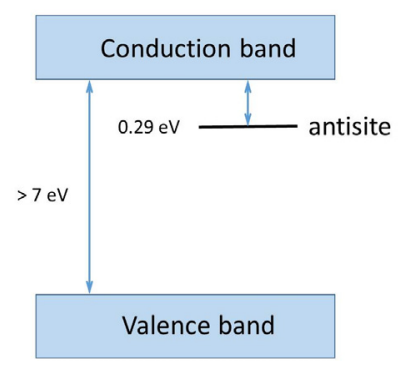

LUGaAG



Figure 11. Schematic of the band structure of undoped LuAG (left) with the antisite defect in the band gap $0.29 \mathrm{eV}$ below the conduction band, compared to the band shift due to Ga admix, where the defect level is no longer in the forbidden gap (From [97]).

The same technique has been applied in $\mathrm{Y}_{3} \mathrm{Al}_{5-x} \mathrm{Ga}_{x} \mathrm{O}_{12}: \mathrm{Ce}^{3+} ; \mathrm{Cr}^{3+}$ samples to control the electron transfer between $\mathrm{Ce}^{3+}$ and $\mathrm{Cr}^{3+}$ [99]. In Figure 12, the TL glow curves are shown for different values $x$ of the Ga content. The observed single TL peak can be attributed to the electron trap of $\mathrm{Cr}^{3+}\left(\mathrm{Cr}^{3+}+\right.$ $\mathrm{e}^{-}$), which is regarded as the state of $\mathrm{Cr}^{2+}$. The peak temperature of the TL glow curve, except for the $x=0$ sample, lowers with increasing Ga content. From Figure 12, it is seen that that the glow curves do not show the shape of the asymmetric first-order glow peak. Ueda et al. explained this behaviour by assuming that the traps in YAGG:Ce-Cr do not have a single depth, but show a trap depth distribution with a width in energy that depends on the Ga content $x$. The trap depth distribution is assumed to be caused by variations in the environment of the defect responsible for the trap. From simulating the distribution, the authors were able to conclude that with increasing $x$, Ga first starts to occupy the tetrahedral sites, and above $x=3$, the octahedral sites are also occupied. Katayama et al. [100] reproduced this result in the same material, but it was co-doped with $\mathrm{Bi}^{3+}$. Luo et al. [101] studied multicomponent garnet scintillators $\left(\mathrm{Lu}_{x} \mathrm{Gd}_{3-x}\right)\left(\mathrm{Ga}_{y} \mathrm{Al}_{5-y}\right) \mathrm{O}_{12}$ : $\mathrm{Ce}(x=0,1,2,3$ and $y=0,1,2,3,4)$ and identified changes in the band gap by monitoring the shift of the corresponding TL glow peaks. All these studies show that TSL is an indispensable experimental tool in understanding the electron transfer mechanism.

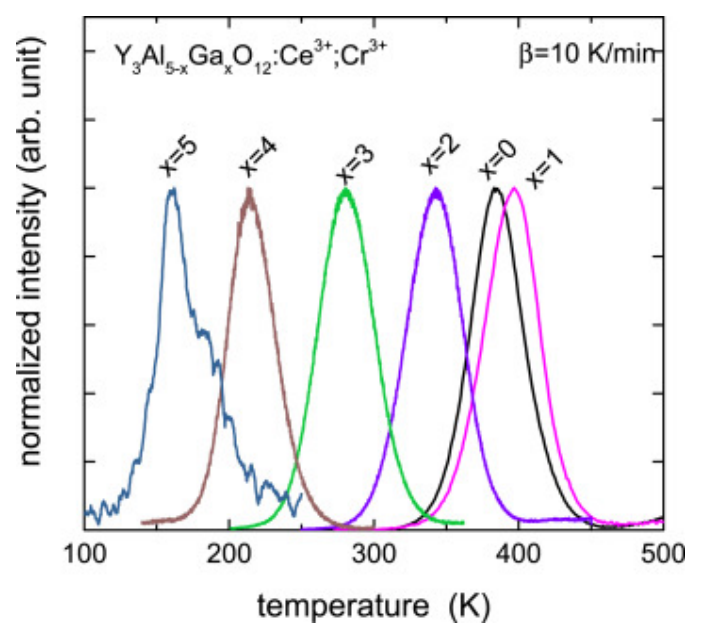

Figure 12. TL glow curves recorded at a heating rate of $\beta=10 \mathrm{~K} / \mathrm{min}$ for $\mathrm{Y}_{3} \mathrm{Al}_{5-x} \mathrm{Ga}_{x} \mathrm{O}_{12}: \mathrm{Ce}^{3+} ; \mathrm{Cr}^{3+}$ with $x=0,1,2,3,4$, and 5, where $\mathrm{Ce}^{3+}$ emission is monitored and electrons are released from $\mathrm{Cr}^{2+}$. Reproduced from Reference [99] with permission from The Royal Society of Chemistry. 


\subsection{Tunnelling}

In the simple model of thermoluminescence (Figure 1), it is assumed that the recombination pathway of the electron goes via the conduction band. However, an alternative pathway is a localized transition where the electron recombines with a nearby hole center via quantum tunnelling. Tunnelling recombination of trapped electrons with holes has been shown in calcite [102] and natural feldspars [103], but also in synthetic phosphors as $\mathrm{Zn}_{2} \mathrm{SiO}_{4}: \mathrm{Mn}$ [104] and $\mathrm{KCl}$ [105]. The tunnelling process is in principle temperature independent. This is illustrated in Figure 13. For $\mathrm{YPO}_{4}: \mathrm{Ce}^{3+}, \mathrm{Ln}^{3+}$, the $\mathrm{Ce}^{3+}$ ion is the stable hole center and the Ln-copants act as trapping centers. The plateau before the main TL glow peak looks like a background, but is in fact temperature independent luminescence caused by a localized transition. No "background" is observed on the high temperature side of the glow peak because the trap is then fully emptied. Quantum tunnelling may be temperature independent but is critically dependent on the distance between the hole and trapping center. So one might expect that this plateau will rise as more hole and trapping centers are available, decreasing the average distance between the recombination center $\left(\mathrm{Ce}^{4+}\right)$ and trapping center $\left(\mathrm{Ln}^{2+}\right)$; in other words, as the concentration of the dopants increases. This has been investigated by Dobrowolska et al. [106]. They developed a model that successfully explained the shape and behaviour of the TL glow curves as a function of the concentration.

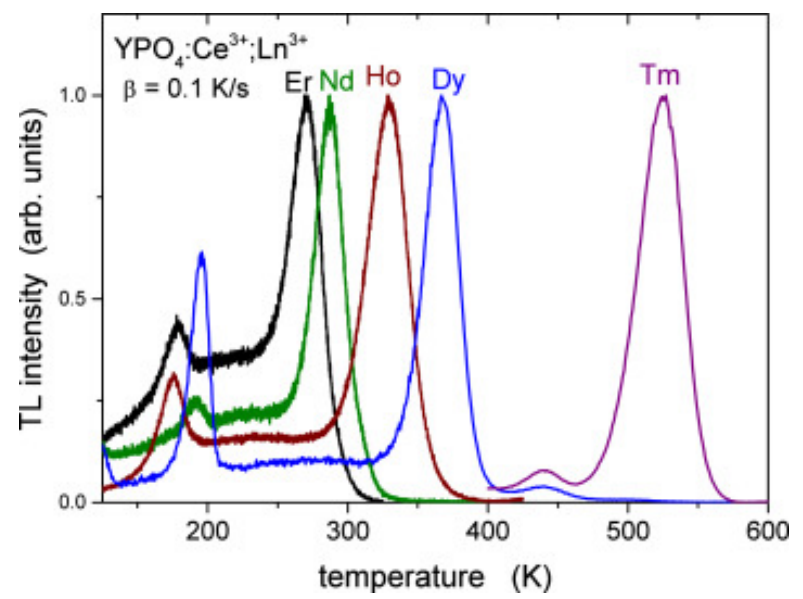

Figure 13. Thermally stimulated glow curves of $\mathrm{YPO}_{4}: \mathrm{Ce}^{3+}, \mathrm{Ln}^{3+}(\mathrm{Ln}=\mathrm{Er}, \mathrm{Nd}, \mathrm{Ho}, \mathrm{Dy}$, and Tm). The plateau before the main peak of the samples with co-dopants $\mathrm{Er}, \mathrm{Nd}, \mathrm{Ho}$, and Dy is caused by tunnelling recombination (localized transition). The main peaks are caused by recombination via the conduction band (non-localized transition).

Another recombination pathway is via an excited state of the trapping centre. This is illustrated in Figure 14 for Ce-doped $\mathrm{Gd}_{3} \mathrm{Al}_{2} \mathrm{Ga}_{3} \mathrm{O}_{12}$ [107]. The population of the excited state is by thermal activation, causing the thermally assisted tunnelling to become temperature dependent. Thermally assisted tunnelling is also described by Vedda et al. [108], who studied the glow curves from $\mathrm{Lu}_{\mathrm{x}} \mathrm{Y}_{2-\mathrm{x}} \mathrm{SiO}_{5}$ :Ce. They show that oxygen vacancies act as electron traps in the material. The presence of several glow peaks with a unique trap depth $(0.99 \mathrm{eV} \pm 0.07 \mathrm{eV})$ for the $78,135,181$, and $236{ }^{\circ} \mathrm{C}$ peaks is explained by suggesting that electrons stored in oxygen vacancies recombine through a thermally assisted tunnelling mechanism with holes localized at $\mathrm{Ce}^{3+}$ centers residing on $\mathrm{Lu}$ sites at different crystallographic distances from the traps. Nowadays, localised recombinations are recognized in many materials and experimentally and theoretically investigated [109-112]. 


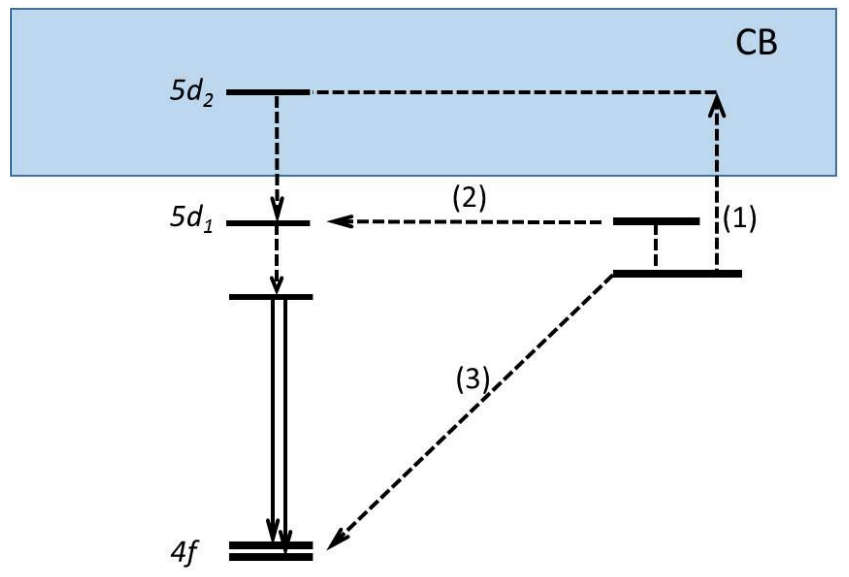

Figure 14. Schematic energy level diagram for the possible recombination pathways of trapped electrons in GAGG:Ce crystal: (1) thermally stimulated non-localized transition (classical TSL), (2) thermally assisted tunnelling, and (3) ground state tunnelling recombination. CB = Conduction Band (Adopted from [107]).

\subsection{Thermal Quenching}

In many phosphors, the luminescent properties depend on the temperature. At a higher temperature, the luminescence can be quenched. For LED phosphors, for example, the thermal quenching temperature of the luminescence is a crucial parameter. Study of the thermal quenching will usually be performed by measuring the photoluminescence as a function of the temperature. But study of the thermally stimulated luminescence glow curve can give additional information. Glow curves measured at different heating rates will produce a glow peak that shifts to a higher temperature (see Figure 3), but the total area will remain constant. However, if there is thermal quenching, the integrated intensity will decrease. Because the low temperature side of the peak will be less affected than the high temperature side, the shape of the peak will be distorted [113]. From variable heating rate measurements, the quenching function can be derived [114]. In some cases, the temperature integrated luminescence intensity increases with an increasing heating rate [106,115]. This so-called anomalous heating rate dependence can be explained by a model that takes into account both localized and non-localized transitions [116]. Through thermoluminescence excitation spectroscopy, insight into the thermal quenching mechanism can be derived [117].

\subsection{Photosynthesis}

Thermally stimulated luminescence can also be observed from biological material. Arnhold and Sherwood [118] were the first who described TL in chloroplasts. The original discovery of TL in chloroplasts later proved to be a phenomenon common to all photosynthetic organisms. Following the initial observations, considerable effort has been devoted to the identification and characterization of photosynthetic TL components. Nowadays, TL is applied as a research tool to study photosynthetic electron transport under various physiological conditions [119]. As mentioned earlier, the technique requires special instrumental features [46] and the theory described in Section 2, stemming from solid-state physics, needs another theoretical framework [44]. Characteristic for photosynthetic systems is recombination that takes place through various routes among which the radiative pathway generally represents a relatively minor share. The radiative route is the one with the largest activation energy and is thus almost absent at a low temperature. Since its discovery, the origin of many TL components have been identified, characterised, and assigned to the redox components of the Photosystem II, which makes TL a versatile tool in photosynthesis research [45,120,121]. 


\section{Conclusions}

Thermally stimulated luminescence is a well-known phenomenon that has been studied for a long time. The measurement of the luminescence is purely optical, showing a high sensitivity, and is applicable to both crystalline and non-crystalline material. The first commercially available TL readers were developed for dosimetry and dating purposes. Nowadays, available readers are also suited for research on luminescent materials and are equipped with different detectors, optical filters, and excitation sources.

The basic explanation of the phenomenon was given by Randall and Wilkins more than 70 years ago. Their model is an oversimplification of a rather complicated situation. Since then, many extensions of the simple model have been given, and nowadays, the theory is being developed to a highly sophisticated level. Each extension of the theory implies an extension of the number of parameters. It has become clear that it is difficult, if not impossible, to extract all parameters. However, one can determine the value of the trap depth with a good accuracy without knowing the other parameters. Applied in combination with other spectroscopic methods like optical absorption emission and excitation spectroscopy, it is highly effective in sensing changes in energy level positions which are crucial for so many luminescent properties.

In the field of luminescence spectroscopy, a wealth of data have been published during the last 70 years. Extensive investigation of all those data have revealed all sorts of trends in energy levels which can be described in semi-empirical models. TL has proven to be the experimental technique for testing those models.

In this review, many examples have been given that show that TL is a powerful tool to study material characteristics and a great help in understanding the underlying mechanism of luminescence, as well as processes affecting light production.

Acknowledgments: I would like to thank E.P.J. Merkx for the language editing of this manuscript.

Conflicts of Interest: The authors declare no conflict of interest.

\section{References}

1. Daniels, F.; Boyd, C.; Saunders, D. Thermoluminescence as a Research Tool. Science 1953, 117, 343-349. [CrossRef] [PubMed]

2. Martini, M.; Meinardi, F. Thermally stimulated luminescence: New perspectives in the study of defects in solids. La Riv. del Nuovo Cim. 1997, 20, 1-71. [CrossRef]

3. Murthy, K.V.R. Thermoluminescence and its Applications: A Review. Defect Diffus. Forum 2013, 347, 35-73. [CrossRef]

4. Mihóková, E.; Nikl, M. Luminescent materials: Probing the excited state of emission centers by spectroscopic methods. Meas. Sci. Technol. 2015, 26, 12001. [CrossRef]

5. Bos, A.J.J. Theory of thermoluminescence. Radiat. Meas. 2006, 41, 45-56. [CrossRef]

6. McKeever, S.W.S. Thermoluminescence of Solids; Cambridge University Press: Cambridge, UK, 1988; ISBN 0521368111.

7. Chen, R.; McKeever, S.W.S. Theory of Thermoluminescence and Related Phenomena; World Scientific: Singapore, 1997; ISBN 0810222955.

8. Chen, R.; Pagonis, V. Thermally and Optically Stimulated Luminescence-A Simulation Approach; John Wiley: Chichester, UK, 2011; ISBN 978-0-470-74927-2.

9. Sunta, C.M. Unraveling Thermoluminescence; Springer Series in Materials Science; Springer: New Delhi, India, 2015; Volume 202, ISBN 978-81-322-1939-2.

10. Randall, J.T.; Wilkins, M.H.F. The Phosphorescence of Various Solids. Proc. R. Soc. A Math. Phys. Eng. Sci. 1945, 184, 347-364. [CrossRef]

11. Randall, J.T.; Wilkins, M.H.F. Phosphorescence and Electron Traps. II. The Interpretation of Long-Period Phosphorescence. Proc. R. Soc. A Math. Phys. Eng. Sci. 1945, 184, 390-407. [CrossRef]

12. Randall, J.; Wilkins, M. Phosphorescence and Electron Traps I. The Study of Trap Distributions. Proc. R. Soc. A Math. Phys. Eng. Sci. 1945, 184, 366-389. [CrossRef] 
13. Hoogenboom, J.E.; De Vries, W.; Dielhof, J.B.; Bos, A.J.J. Computerized analysis of glow curves from thermally activated processes. J. Appl. Phys. 1988, 64, 3193-3200. [CrossRef]

14. Urbach, F. Zur Lumineszenz der Alkalihalogenide. Sitzungsberichte Akad. der Wiss. Wien 1930, 139, $363-372$. [CrossRef]

15. Murthy, K.V.R.; Virk, H.S. Luminescence Phenomena: An Introduction. Defect Diffus. Forum 2014, 347, 1-34. [CrossRef]

16. Pagonis, V.; Kitis, G. Prevalence of first-order kinetics in thermoluminescence materials: An explanation based on multiple competition processes. Phys. Status Solidi Basic Res. 2012, 249, 1590-1601. [CrossRef]

17. Pagonis, V.; Morthekai, P.; Kitis, G. Kinetic analysis of thermoluminescence glow curves in feldspar: Evidence for a continuous distribution of energies. Geochronometria 2014, 41, 168-177. [CrossRef]

18. Gómez-Ros, J.M.; Correcher, V.; García-Guinea, J.; Delgado, A. Evolution of the trapped charge distribution due to trap emptying processes in a natural aluminosilicate. Radiat. Prot. Dosim. 2006, 119, 93-97. [CrossRef] [PubMed]

19. Correcher, V.; Gomez-Ros, J.M.; Garcia-Guinea, J.; Lis, M.; Sanchez-Muñoz, L. Calculation of the activation energy in a continuous trap distribution system of a charoite silicate using initial rise and TL glow curve fitting methods. Radiat. Meas. 2008, 43, 269-272. [CrossRef]

20. Srivastava, J.K.; Supe, S.J. Trap distribution analysis for thermoluminescence of $\mathrm{CaSO}_{4}: D y . \quad J$. Phys. D Appl. Phys. 1983, 16, 1813-1818. [CrossRef]

21. Srivastava, J.K.; Supe, S.J. The thermoluminescence characterisation of $\mathrm{Li}_{2} \mathrm{~B}_{4} \mathrm{O}_{7}$ doped with Cu. J. Phys. D Appl. Phys. 1989, 22, 1537-1543. [CrossRef]

22. Whitley, V.H.; Larsen, N.A.; McKeever, S.W.S. Determination of ionisation energies and attempt-to-escape factors using thermally stimulated conductivity. Radiat. Prot. Dosim. 2002, 100, 147-152. [CrossRef]

23. Botterman, J.; Smet, P.F. Persistent phosphor $\mathrm{SrAl}_{2} \mathrm{O}_{4}: \mathrm{Eu}$,Dy in outdoor conditions: Saved by the trap distribution. Opt. Express 2015, 23, A868-A881. [CrossRef] [PubMed]

24. Aitasalo, T.; Hölsä, J.; Jungner, H.; Krupa, J.-C.; Lastusaari, M.; Legendziewicz, J.; Niittykoski, J. Effect of temperature on the luminescence processes of $\mathrm{SrAl}_{2} \mathrm{O}_{4}: \mathrm{Eu}^{2+}$. Radiat. Meas. 2004, 38, 727-730. [CrossRef]

25. Van Den Eeckhout, K.; Bos, A.J.J.; Poelman, D.; Smet, P.F. Revealing trap depth distributions in persistent phosphors. Phys. Rev. B-Condens. Matter Mater. Phys. 2013, 87, 1-11. [CrossRef]

26. Pan, Z.; Lu, Y.-Y.; Liu, F. Sunlight-activated long-persistent luminescence in the near-infrared from $\mathrm{Cr}^{3+}$-doped zinc gallogermanates. Nat. Mater. 2011, 11, 58-63. [CrossRef] [PubMed]

27. Zhuang, Y.; Ueda, J.; Tanabe, S.; Dorenbos, P. Band-gap variation and a self-redox effect induced by compositional deviation in $\mathrm{Zn}_{\mathrm{x}} \mathrm{Ga}_{2} \mathrm{O}_{3+\mathrm{x}}: \mathrm{Cr}^{3+}$ persistent phosphors. J. Mater. Chem. C 2014, 2, 5502. [CrossRef]

28. Guo, H.; Wang, Y.; Chen, W.; Zeng, W.; Han, S.; Li, G.; Li, Y. Controlling and revealing the trap distributions of $\mathrm{Ca}_{6} \mathrm{BaP}_{4} \mathrm{O}_{17}: \mathrm{Eu}^{2+}, \mathrm{R}^{3+}(\mathrm{R}=\mathrm{Dy}, \mathrm{Tb}, \mathrm{Ce}, \mathrm{Gd}, \mathrm{Nd})$ by codoping different trivalent lanthanides. J. Mater. Chem. C 2015, 3, 11212-11218. [CrossRef]

29. Wang, J.; Zhang, H.; Liu, Y.; Dong, H.; Lei, B.; Zheng, M.; Xiao, Y.; Peng, M.; Wang, J. Insights into luminescence quenching and detecting trap distribution in $\mathrm{Ba}_{2} \mathrm{Si}_{5} \mathrm{~N}_{8}: \mathrm{Eu}^{2+}$ phosphor with comprehensive considerations of temperature-dependent luminescence behaviors. J. Mater. Chem. C 2015, 3, 9572-9579. [CrossRef]

30. Brylew, K.; Drozdowski, W.; Wojtowicz, A.J.; Kamada, K.; Yoshikawa, A. Studies of low temperature thermoluminescence of GAGG:Ce and LuAG:Pr scintillator crystals using the $T_{\max }-T_{\text {stop }}$ method. J. Lumin. 2014, 154, 452-457. [CrossRef]

31. Lecointre, A.; Bessière, A.; Bos, A.J.J.; Dorenbos, P.; Viana, B.; Jacquart, S. Designing a red persistent luminescence phosphor: The example of $\mathrm{YPO}_{4}: \mathrm{Pr}^{3+}, \mathrm{Ln}^{3+}(\mathrm{Ln}=\mathrm{Nd}, \mathrm{Er}, \mathrm{Ho}, \mathrm{Dy})$. J. Phys. Chem. C 2011, 115, 4217-4227. [CrossRef]

32. Luo, H.; Bos, A.J.J.; Dorenbos, P. Charge Carrier Trapping Processes in $\mathrm{RE}_{2} \mathrm{O}_{2} \mathrm{~S}(\mathrm{RE}=\mathrm{La}, \mathrm{Gd}, \mathrm{Y}$ and Lu). J. Phys. Chem. C 2017. [CrossRef] [PubMed]

33. Hoogenstraaten, W. Electron traps in ZnS phosphors. Philips Res. Rep. 1958, 13, 515-693.

34. Kitis, G.; Tuyn, J.W.N. A simple method to correct for the temperature lag in TL glow-curve measurements. J. Phys. D. Appl. Phys. 1998, 31, 2065-2073. [CrossRef]

35. Piters, T.M.; Bos, A.J.J. Effects of non-ideal heat transfer on the glow curve in thermoluminescence experiments. J. Phys. D Appl. Phys. 1999, 27, 1747-1756. [CrossRef] 
36. Garlick, G.F.J.; Gibson, A.F. The Electron Trap Mechanism of Luminescence in Sulphide and Silicate Phosphors. Proc. Phys. Soc. 1948, 60, 574-590. [CrossRef]

37. Pagonis, V.; Kitis, G.; Furetta, C. Numerical and Practical Exercises in Thermoluminescence; Springer: New York, NY, USA, 2006; ISBN 0-387-26063-3.

38. Chen, R.; Haber, G.A. Calculation of glow curves' activation energies by numerical initial rise method. Chem. Phys. Lett. 1968, 2, 483-485. [CrossRef]

39. Horowitz, Y.S.; Yossin, D. Computerized Glow curve deconvolution: Application to thermoluminescence dosimetry. Radiat. Prot. Dosim. 1995, 60, 1-114.

40. Van Dijk, J.W.E. Thermoluminescence glow curve deconvolution and its statistical analysis using the flexibility of spreadsheet programs. Radiat. Prot. Dosim. 2006, 119, 332-338. [CrossRef] [PubMed]

41. Stadtmann, H.; Wilding, G. Glow curve deconvolution for the routine readout of $\mathrm{LiF}: \mathrm{Mg}$, Ti thermoluminescent detectors. Radiat. Meas. 2017. [CrossRef]

42. Chen, R.; Pagonis, V.; Lawless, J.L. Evaluated thermoluminescence trapping parameters-What do they really mean? Radiat. Meas. 2016, 91, 21-27. [CrossRef]

43. Chen, R.; Pagonis, V. The role of simulations in the study of thermoluminescence (TL). Radiat. Meas. 2014, 71, 8-14. [CrossRef]

44. Rappaport, F.; Lavergne, J. Thermoluminescence: Theory. Photosynth. Res. 2009, 101, 205-216. [CrossRef] [PubMed]

45. Repetto, G.; Zurita, J.L.; Roncel, M.; Ortega, J.M. Thermoluminescence as a complementary technique for the toxicological evaluation of chemicals in photosynthetic organisms. Aquat. Toxicol. 2015, 158, 88-97. [CrossRef] [PubMed]

46. Ducruet, J.M.; Vass, I. Thermoluminescence: Experimental. Photosynth. Res. 2009, 101, 195-204. [CrossRef] [PubMed]

47. Townsend, P.D.; Kirsh, Y. Spectral measurement during thermoluminescence-An essential requirement. Contemp. Phys. 1989, 30, 337-354. [CrossRef]

48. Piters, T.M.; Meulemans, W.H.; Bos, A.J.J. An automated research facility for measuring thermoluminescence emission spectra using an optical multichannel analyzer. Rev. Sci. Instrum. 1993, 64, 109. [CrossRef]

49. Rhodes, M.W.; Wanwilairat, S.; Vilaithong, T.; Hoffmann, W. Low cost high resolution thermoluminescence spectrometer. Rev. Sci. Instrum. 2000, 71, 2053. [CrossRef]

50. Bos, A.J.J.; Winkelman, A.J.M.; Le Masson, N.J.M.; Sidorenko, A.V.; Van Eijk, C.W. A TL/OSL Emission Spectrometer Extension of the. Radiat. Meas. 2002, 101, 111-114.

51. Yoshizumi, M.T.; Caldas, L.V.E. TL emission spectra measurements using a spectrometer coupled to the Risoe TL/OSL reader. Radiat. Phys. Chem. 2014, 104, 292-296. [CrossRef]

52. Bos, A.J.J.; Dorenbos, P.; Bessière, A.; Viana, B. Lanthanide energy levels in $\mathrm{YPO}_{4}$. Radiat. Meas. 2008, 43, 222-226. [CrossRef]

53. Bos, A.J.J.; Van Duijvenvoorde, R.M.; Van Der Kolk, E.; Drozdowski, W.; Dorenbos, P. Thermoluminescence excitation spectroscopy: A versatile technique to study persistent luminescence phosphors. J. Lumin. 2011, 131, 1465-1471. [CrossRef]

54. Thomsen, K.J.; Bøtter-Jensen, L.; Jain, M.; Denby, P.M.; Murray, A.S. Recent instrumental developments for trapped electron dosimetry. Radiat. Meas. 2008, 43, 414-421. [CrossRef]

55. Lapp, T.; Jain, M.; Thomsen, K.J.; Murray, A.S.; Buylaert, J.P. New luminescence measurement facilities in retrospective dosimetry. Radiat. Meas. 2012, 47, 803-808. [CrossRef]

56. Lapp, T.; Kook, M.; Murray, A.S.; Thomsen, K.J.; Buylaert, J.P.; Jain, M. A new luminescence detection and stimulation head for the Risø TL/OSL reader. Radiat. Meas. 2014, 81, 178-184. [CrossRef]

57. Richter, D.; Richter, A.; Dornich, K. Lexsyg_A new system for luminescence research. Geochronometria 2013, 40, 220-228. [CrossRef]

58. Richter, D.; Richter, A.; Dornich, K. Lexsyg smart-A luminescence detection system for dosimetry, material research and dating application. Geochronometria 2015, 42, 202-209. [CrossRef]

59. Richter, D.; Mittelstraß, D.; Kreutzer, S.; Pintaske, R.; Dornich, K.; Fuchs, M. A new fully integrated X-ray irradiator system for dosimetric research. Appl. Radiat. Isot. 2016, 112, 122-130. [CrossRef] [PubMed]

60. Dorenbos, P. Systematic behaviour in trivalent lanthanide charge transfer energies. J. Phys. Condens. Matter 2003, 15, 8417-8434. [CrossRef] 
61. Dorenbos, P. A Review on How Lanthanide Impurity Levels Change with Chemistry and Structure of Inorganic Compounds. ECS J. Solid State Sci. Technol. 2013, 2, R3001-R3011. [CrossRef]

62. Dorenbos, P. The electronic structure of lanthanide doped compounds with $3 \mathrm{~d}, 4 \mathrm{~d}, 5 \mathrm{~d}$, or $6 \mathrm{~d}$ conduction band states. J. Lumin. 2014, 151, 224-228. [CrossRef]

63. Dorenbos, P. Charge transfer bands in optical materials and related defect level location. Opt. Mater. (Amst) 2017, 69, 8-22. [CrossRef]

64. Dorenbos, P. Valence stability of lanthanide ions in inorganic compounds. Chem. Mater. 2005, 17, $6452-6456$. [CrossRef]

65. Bos, A.J.J.; Dorenbos, P.; Bessire, A.; Lecointre, A.; Bedu, M.; Bettinelli, M.; Piccinelli, F. Study of TL glow curves of $\mathrm{YPO}_{4}$ double doped with lanthanide ions. Radiat. Meas. 2011, 46, 1410-1416. [CrossRef]

66. You, F.; Bos, A.J.J.; Shi, Q.; Huang, S.; Dorenbos, P. Thermoluminescence investigation of donor $\left(\mathrm{Ce}^{3+}, \mathrm{Pr}^{3+}\right.$, $\left.\mathrm{Tb}^{3+}\right)$ acceptor $\left(\mathrm{Eu}^{+}, \mathrm{Yb}^{3+}\right)$ pairs in $\mathrm{Y}_{3} \mathrm{Al}_{5} \mathrm{O}_{12}$. Phys. Rev. B-Condens. Matter Mater. Phys. 2012, 85, 1-7. [CrossRef]

67. Krumpel, A.H.; Bos, A.J.J.; Bessière, A.; Van Der Kolk, E.; Dorenbos, P. Controlled electron and hole trapping in $\mathrm{YPO}_{4}: \mathrm{Ce}^{3+}, \mathrm{Ln}^{3+}$ and $\mathrm{LuPO}_{4}: \mathrm{Ce}^{3+}, \mathrm{Ln}^{3+}(\mathrm{Ln}=\mathrm{Sm}, \mathrm{Dy}, \mathrm{Ho}, \mathrm{Er}, \mathrm{Tm})$. Phys. Rev. B-Condens. Matter Mater. Phys. 2009, 80, 1-10. [CrossRef]

68. Luo, H.; Bos, A.J.J.; Dobrowolska, A. Low-temperature VUV photoluminescence and thermoluminescence of UV excited afterglow phosphor $\mathrm{Sr}_{3} \mathrm{Al}_{\mathrm{x}} \mathrm{Si}_{1-\mathrm{x}} \mathrm{O}_{5}: \mathrm{Ce}^{3+}, \mathrm{Ln}^{3+}(\mathrm{Ln}=\mathrm{Er}, \mathrm{Nd}, \mathrm{Sm}, \mathrm{Dy}$ and Tm). Phys. Chem. Chem. Phys. 2015, 17, 15419-15427. [CrossRef] [PubMed]

69. Yukihara, E.G.; Milliken, E.D.; Oliveira, L.C.; Orante-Barrón, V.R.; Jacobsohn, L.G.; Blair, M.W. Systematic development of new thermoluminescence and optically stimulated luminescence materials. J. Lumin. 2013, 133, 203-210. [CrossRef]

70. Oliveira, L.C.; Yukihara, E.G.; Baffa, O. MgO:Li,Ce,Sm as a high-sensitivity material for Optically Stimulated Luminescence dosimetry. Sci. Rep. 2016, 6, 24348. [CrossRef] [PubMed]

71. Luo, H.; Bos, A.J.J.; Dorenbos, P. Controlled Electron-Hole Trapping and Detrapping Process in GdAlO3 by Valence Band Engineering. J. Phys. Chem. C 2016, 120, 5916-5925. [CrossRef]

72. You, F.; Bos, A.J.J.; Shi, Q.; Huang, S.; Dorenbos, P. Electron transfer process between $\mathrm{Ce}^{3+}$ donor and $\mathrm{Yb}^{3+}$ acceptor levels in the bandgap of $\mathrm{Y}_{3} \mathrm{Al}_{5} \mathrm{O}_{12}$ (YAG). J. Phys. Condens. Matter 2011, 23, 215502. [CrossRef] [PubMed]

73. Hamilton, D.S.; Gayen, S.K.; Pogatshnik, G.J.; Ghen, R.D.; Miniscalco, W.J. Optical-absorption and photoionization measurements from the excited states of $\mathrm{Ce}^{3+}: \mathrm{Y}_{3} \mathrm{Al}_{5} \mathrm{O}_{12}$. Phys. Rev. B 1989, 39, 8807-8815. [CrossRef]

74. Babin, V.; Hanus, M.; Krasnikov, A.; Kučera, M.; Nikl, M.; Zazubovich, S. Determination of the position of the $5 \mathrm{~d}$ excited levels of $\mathrm{Ce}^{3+}$ ions with respect to the conduction band in the epitaxial films of the multicomponent $(\mathrm{Lu}, \mathrm{Gd})_{3}(\mathrm{Ga}, \mathrm{Al})_{5} \mathrm{O}_{12}:$ Ce garnets. Opt. Mater. (Amst) 2016, 62, 465-474. [CrossRef]

75. Wu, Y.; Nikl, M.; Jary, V.; Ren, G. Thermally induced ionization of $5 \mathrm{~d}_{1}$ state of $\mathrm{Ce}^{3+}$ ion in $\mathrm{Gd}_{3} \mathrm{Ga}_{3} \mathrm{Al}_{2} \mathrm{O}_{12}$ host. Chem. Phys. Lett. 2013, 574, 56-60. [CrossRef]

76. Matsuzawa, T.; Aoki, Y.; Takeuchi, N.; Murayama, Y. A New Long Phosphorescent Phosphor with High Brightness, $\mathrm{SrAl}_{2} \mathrm{O}_{4}: \mathrm{Eu}^{2+}, \mathrm{Dy}^{3+}$. J. Electrochem. Soc. 1996, 143, 2670. [CrossRef]

77. Ueda, J.; Hashimoto, A.; Takemura, S.; Ogasawara, K.; Dorenbos, P.; Tanabe, S. Vacuum referred binding energy of $3 \mathrm{~d}$ transition metal ions for persistent and photostimulated luminescence phosphors of cerium-doped garnets. J. Lumin. 2017, 192, 371-375. [CrossRef]

78. Aitasalo, T.; Ho, J.; Lastusaari, M.; Niittykoski, J. Thermoluminescence Study of Persistent Luminescence Materials: $\mathrm{Eu}^{2+}$ - and $\mathrm{R}^{3+}$-Doped Calcium Aluminates, $\mathrm{CaAl}_{2} \mathrm{O}_{4}: \mathrm{Eu}^{2+}, \mathrm{R}^{3+}$. J. Phys. Chem. B 2006, 110, 4589-4598. [CrossRef] [PubMed]

79. Asami, K.; Ueda, J.; Tanabe, S. Trap depth and color variation of $\mathrm{Ce}^{3+}-\mathrm{Cr}^{3+}$ co-doped $\mathrm{Gd}_{3}(\mathrm{Al}, \mathrm{Ga})_{5} \mathrm{O}_{12}$ garnet persistent phosphors. Opt. Mater. (Amst) 2016, 62, 171-175. [CrossRef]

80. Bessière, A.; Lecointre, A.; Priolkar, K.R.; Gourier, D. Role of crystal defects in red long-lasting phosphorescence of $\mathrm{CaMgSi}_{2} \mathrm{O}_{6}: \mathrm{Mn}$ diopsides. J. Mater. Chem. 2012, 22, 19039. [CrossRef]

81. Brito, H.F.; Hölsä, J.; Jungner, H.; Laamanen, T.; Lastusaari, M.; Malkamäki, M.; Rodrigues, L.C.V. Persistent luminescence fading in $\mathrm{Sr}_{2} \mathrm{MgSi}_{2} \mathrm{O}_{7}: \mathrm{Eu}^{2+}, \mathrm{R}^{3+}$ materials: A thermoluminescence study. Opt. Mater. Express 2012, 2, 287. [CrossRef] 
82. Denis, G.; Deniard, P.; Rocquefelte, X.; Benabdesselam, M.; Jobic, S. The thermally connected traps model applied to the thermoluminescence of $\mathrm{Eu}^{2+}$ doped $\mathrm{Ba}_{13-\mathrm{x}} \mathrm{Al}_{22-2 \mathrm{x}} \mathrm{Si}_{10+2 \mathrm{x}} \mathrm{O}_{66}$ materials (x 0.6). Opt. Mater. (Amst) 2010, 32, 941-945. [CrossRef]

83. Dobrowolska, A.; Karsu, E.C.; Bos, A.J.J.; Dorenbos, P. Spectroscopy, thermoluminescence and afterglow studies of $\mathrm{CaLa}_{4}\left(\mathrm{SiO}_{4}\right)_{3} \mathrm{O}: \mathrm{Ln}(\mathrm{Ln}=\mathrm{Ce}, \mathrm{Nd}, \mathrm{Eu}, \mathrm{Tb}, \mathrm{Dy})$. J. Lumin. 2015, 160, 321-327. [CrossRef]

84. Feng, P.; Zhang, J.; Wu, C.; Liu, X.; Wang, Y. Self-activated afterglow luminescence of un-doped $\mathrm{Ca}_{2} \mathrm{ZrSi}_{4} \mathrm{O}_{12}$ material and explorations of new afterglow phosphors in a rare earth element-doped $\mathrm{Ca}_{2} \mathrm{ZrSi}_{4} \mathrm{O}_{12}$ system. Mater. Chem. Phys. 2013, 141, 495-501. [CrossRef]

85. Ju, G.; Hu, Y.; Chen, L.; Wang, X. Investigation of the persistent luminescence of $\mathrm{LiBaPO}_{4}: \mathrm{Eu}^{2+}$. J. Mater. Res. 2014, 29, 519-526. [CrossRef]

86. Katayama, Y.; Kobayashi, H.; Ueda, J.; Viana, B.; Tanabe, S. Persistent luminescence properties of $\mathrm{Cr}^{3+}-\mathrm{Sm}^{3+}$ activated $\mathrm{LaAlO}_{3}$ perovskite. Opt. Mater. Express 2016, 6, 1500. [CrossRef]

87. Li, Y.; Gecevicius, M.; Qiu, J. Long persistent phosphors-From fundamentals to applications. Chem. Soc. Rev. 2016, 45, 2090-2136. [CrossRef] [PubMed]

88. Liepina, V.; Millers, D.; Smits, K. Tunneling luminescence in long lasting afterglow of $\mathrm{SrAl}_{2} \mathrm{O}_{4}: \mathrm{Eu}_{\text {, }} \mathrm{Dy}$. J. Lumin. 2017, 185, 151-154. [CrossRef]

89. Rosticher, C.; Chaneac, C.; Bos, A.J.J.; Viana, B. Study on the persistent luminescence of diopside nanotracers $\mathrm{CaMgSi}_{2} \mathrm{O}_{6}: \mathrm{Eu}^{2+}, \mathrm{Mn}^{2+}, \mathrm{Pr}^{3+}$. Proc. SPIE 2016, 9749, 97490-97491. [CrossRef]

90. Singh, T.B.; Mashangva, M.; Gartia, R.K. Trap spectroscopy and thermoluminescence of persistent luminescent materials. Indian J. Pure Appl. Phys. 2013, 51, 223-229.

91. Tang, W.; Wang, M.; Meng, X.; Lin, W. Luminescence properties of tunable white-light long-lasting phosphor $\mathrm{YPO}_{4}: \mathrm{Eu}^{3+}, \mathrm{Tb}^{3+}, \mathrm{Sr}^{2+}, \mathrm{Zr}^{4+}$. Opt. Mater. (Amst) 2016, 54, 120-125. [CrossRef]

92. Van den Eeckhout, K.; Poelman, D.; Smet, P. Persistent Luminescence in Non-Eu ${ }^{2+}$-Doped Compounds: A Review. Materials (Basel) 2013, 6, 2789-2818. [CrossRef] [PubMed]

93. Van den Eeckhout, K.; Smet, P.F.; Poelman, D. Persistent Luminescence in $\mathrm{Eu}^{2+}$-Doped Compounds: A Review. Materials (Basel) 2010, 3, 2536-2566. [CrossRef]

94. Zhang, J.; Ma, X.; Qin, Q.; Shi, L.; Sun, J.; Zhou, M.; Liu, B.; Wang, Y. The synthesis and afterglow luminescence properties of a novel red afterglow phosphor: $\mathrm{SnO}_{2}: \mathrm{Sm}^{3+}, \mathrm{Zr}^{4+}$. Mater. Chem. Phys. 2012, 136, 320-324. [CrossRef]

95. Zúñiga-Rivera, N.J.; Salas-Castillo, P.; Chernov, V.; Díaz-Torres, L.A.; Meléndrez, R.; García-Gutierrez, R.; Carrillo-Torres, R.C.; Barboza-Flores, M. Thermally and optically stimulated luminescence in long persistent orthorhombic strontium aluminates doped with Eu, Dy and Eu, Nd. Opt. Mater. (Amst) 2017, 67, 91-97. [CrossRef]

96. Zuo, Y.; Chen, X.; Liu, X. Long lasting phosphorescence properties and multi-peak fitting on thermoluminescence of red $\mathrm{LaAlO}_{3}: \mathrm{Eu}^{3+}$ phosphor. Chem. Res. Chin. Univ. 2015, 31, 427-429. [CrossRef]

97. Fasoli, M.; Vedda, A.; Nikl, M.; Jiang, C.; Uberuaga, B.P.; Andersson, D.A.; McClellan, K.J.; Stanek, C.R. Band-gap engineering for removing shallow traps in rare-earth $\mathrm{Lu}_{3} \mathrm{Al}_{5} \mathrm{O}_{12}$ garnet scintillators using $\mathrm{Ga}^{3+}$ doping. Phys. Rev. B-Condens. Matter Mater. Phys. 2011, 84, 1-4. [CrossRef]

98. Nikl, M.; Mihokova, E.; Pejchal, J.; Vedda, A.; Zorenko, Y.; Nejezchleb, K. The antisite LuAl defect-related trap in $\mathrm{Lu}_{3} \mathrm{Al}_{5} \mathrm{O}_{12}$ :Ce single crystal. Phys. Status Solidi 2005, 242, R119-R121. [CrossRef]

99. Ueda, J.; Dorenbos, P.; Bos, A.J.J.; Kuroishi, K.; Tanabe, S. Control of electron transfer between $\mathrm{Ce}^{3+}$ and Cr $^{3+}$ in the $\mathrm{Y}_{3} \mathrm{Al}_{5-x} \mathrm{Ga}_{x} \mathrm{O}_{12}$ host via conduction band engineering. J. Mater. Chem. C 2015, 12, 19-21. [CrossRef]

100. Katayama, Y.; Hashimoto, A.; Xu, J.; Ueda, J.; Tanabe, S. Thermoluminescence investigation on $\mathrm{Y}_{3} \mathrm{Al}_{5-\mathrm{x}} \mathrm{Ga}_{\mathrm{x}} \mathrm{O}_{12}: \mathrm{Ce}^{3+}-\mathrm{Bi}^{3+}$ green persistent phosphors. J. Lumin. 2017, 183, 355-359. [CrossRef]

101. Luo, J.; Wu, Y.; Zhang, G.; Zhang, H.; Ren, G. Composition-property relationships in $\left(\mathrm{Gd}_{3-x} \mathrm{Lu}_{x}\right)\left(\mathrm{GayAl}_{5-y}\right) \mathrm{O}_{12}: \mathrm{Ce}(x=0,1,2,3$ and $y=0,1,2,3,4)$ multicomponent garnet scintillators. Opt. Mater. (Amst) 2013, 36, 476-481. [CrossRef]

102. Visocekas, R.; Ceva, T.; Marti, C.; Lefaucheux, F.; Robert, M.C. Tunneling processes in afterglow of calcite. Phys. Status Solidi 1976, 35, 315-327. [CrossRef]

103. Visocekas, R.; Barthou, C.; Blanc, P. Thermal quenching of far-red $\mathrm{Fe}^{3+}$ thermoluminescence of volcanic K-feldspars. Radiat. Meas. 2014, 61, 52-73. [CrossRef]

104. Avouris, P.; Morgan, T.N. A tunneling model for the decay of luminescence in inorganic phosphors: The case of $\mathrm{Zn}_{2} \mathrm{SiO}_{4}: \mathrm{Mn}$. J. Chem. Phys. 1981, 74, 4347-4355. [CrossRef] 
105. Delbecq, C.J.; Toyozaka, Y.; Yuster, P.H. Tunneling recombination of trapped electrons and holes in $\mathrm{KCl}$ : $\mathrm{AgCl}$ and KCl: TlCl. Phys. Rev. B 1974, 9, 4497-4505. [CrossRef]

106. Dobrowolska, A.; Bos, A.J.J.; Dorenbos, P. Electron tunnelling phenomena in $\mathrm{YPO}_{4}$ : Ce,Ln $(\mathrm{Ln}=\mathrm{Er}, \mathrm{Ho}, \mathrm{Nd}$, Dy). J. Phys. D Appl. Phys. 2014, 47, 335301. [CrossRef]

107. Kitaura, M.; Sato, A.; Kamada, K.; Ohnishi, A.; Sasaki, M. Phosphorescence of Ce-doped $\mathrm{Gd}_{3} \mathrm{Al}_{2} \mathrm{Ga}_{3} \mathrm{O}_{12}$ crystals studied using luminescence spectroscopy. J. Appl. Phys. 2014, 115, 83517. [CrossRef]

108. Vedda, A.; Nikl, M.; Fasoli, M.; Mihokova, E.; Pejchal, J.; Dusek, M.; Ren, G.; Stanek, C.R.; McClellan, K.J.; Byler, D.D. Thermally stimulated tunneling in rare-earth-doped oxyorthosilicates. Phys. Rev. B-Condens. Matter Mater. Phys. 2008, 78, 1-8. [CrossRef]

109. Poolton, N.R.J.; Kars, R.H.; Wallinga, J.; Bos, A.J.J. Direct evidence for the participation of band-tails and excited-state tunnelling in the luminescence of irradiated feldspars. J. Phys. Condens. Matter 2009, 21, 485505. [CrossRef] [PubMed]

110. Şahiner, E.; Kitis, G.; Pagonis, V.; Meriç, N.; Polymeris, G.S. Tunnelling recombination in conventional, post-infrared and post-infrared multi-elevated temperature IRSL signals in microcline K-feldspar. J. Lumin. 2017, 188, 514-523. [CrossRef]

111. Jain, M.; Guralnik, B.; Andersen, M.T. Stimulated luminescence emission from localized recombination in randomly distributed defects. J. Phys. Condens. Matter 2012, 24, 385402. [CrossRef] [PubMed]

112. Pagonis, V.; Chen, R.; Kulp, C.; Kitis, G. An overview of recent developments in luminescence models with a focus on localized transitions. Radiat. Meas. 2017. [CrossRef]

113. Akselrod, M.S.; Agersnap Larsen, N.; Whitley, V.; McKeever, S.W.S. Thermal quenching of F-center luminescence in $\mathrm{Al}_{2} \mathrm{O}_{3}$ :C. J. Appl. Phys. 1998, 84, 3364-3373. [CrossRef]

114. Mandowski, A.; Bos, A.J.J.; Mandowska, E.; Orzechowski, J. Monte-Carlo method for determining the quenching function from variable heating rate measurements. Radiat. Meas. 2010, 45, 284-287. [CrossRef]

115. Bos, A.J.J.; Poolton, N.R.J.; Wallinga, J.; Bessire, A.; Dorenbos, P. Energy levels in $\mathrm{YPO}_{4}: \mathrm{Ce}^{3+}, \mathrm{Sm}^{3+}$ studied by thermally and optically stimulated luminescence. Radiat. Meas. 2010, 45, 343-346. [CrossRef]

116. Mandowski, A.; Bos, A.J.J. Explanation of anomalous heating rate dependence of thermoluminescence in $\mathrm{YPO}_{4}: \mathrm{Ce}^{3+}, \mathrm{Sm}^{3+}$ based on the semi-localized transition (SLT) model. Radiat. Meas. 2011, 46, 1376-1379. [CrossRef]

117. Ueda, J.; Dorenbos, P.; Bos, A.J.J.; Meijerink, A.; Tanabe, S. Insight into the Thermal Quenching Mechanism for $\mathrm{Y}_{3} \mathrm{Al}_{5} \mathrm{O}_{12}: \mathrm{Ce}^{3+}$ through Thermoluminescence Excitation Spectroscopy. J. Phys. Chem. C 2015, 119, 25003-25008. [CrossRef]

118. Arnold, B.Y.W.; Sherwood, H.K. Are Chloroplasts Semiconductors? Proc. Natl. Acad. Sci. USA 1957, 43, 105-114. [CrossRef]

119. Vass, I. The history of photosynthetic thermoluminescence. Photosynth. Res. 2003, 76, 303-318. [CrossRef] [PubMed]

120. Ducruet, J.-M. Chlorophyll thermoluminescence of leaf discs: simple instruments and progress in signal interpretation open the way to new ecophysiological indicators. J. Exp. Bot. 2003, 54, 2419-2430. [CrossRef] [PubMed]

121. Havaux, M. Spontaneous and thermoinduced photon emission: New methods to detect and quantify oxidative stress in plants. Trends Plant Sci. 2003, 8, 409-413. [CrossRef]

(C) 2017 by the author. Licensee MDPI, Basel, Switzerland. This article is an open access article distributed under the terms and conditions of the Creative Commons Attribution (CC BY) license (http:/ / creativecommons.org/licenses/by/4.0/). 